\title{
THERMAL ANALYSIS OF A FLAT-PLATE COLLECTOR IN MULTIPHASE FLOWS, INCLUDING SUPERHEAT
}

\author{
AHMEd Y. El-AsSY* and JohN A. Clark \\ Department of Mechanical Engineering and Applied Mechanics, Solar Energy Laboratory. \\ The University of Michigan, Ann Arbor, Michigan 48109, U.S.A.
}

\begin{abstract}
A thermal analysis of the performance of a solar flat-plate collector operating in nonboiling. boiling, and superheated regimes is presented. The performance of the collector under these single and multiphase conditions is governed by the axial fractional channel lengths of the subcooled (nonboiling) and the superheated regions. The overall thermal loss coefficient, the dimensionless capacitance rate, and collector efficiency factors for various collector operating regions are defined. A new "Generalized Heat Removal Factor," $\mathscr{F}_{s}$, and a new overall thermal loss coefficient, $U_{L}$, for flat-plate collectors under any operation mode are developed. The thermal efficiency a flat-plate collector, whether under nonboiling. boiling, or superheated conditions, is evaluated using $\mathscr{F}_{s}$ and $U_{L}$. It is shown that the value of $\mathscr{F}_{s}$ decreases and the value of $U_{L}$ increases as the degree of superheat increases. Current applications of flatplate collectors having multiphase flows are represented by those charged with refrigerants.
\end{abstract}

\section{INTRODUCTION}

In 1942, the first detailed study of the performance of flat-plate collectors by Hottel and Woertz[1] was based on a thermal analysis of measurements taken from an array of collectors on an experimental solarheated building. They developed a basic procedure for the calculation of thermal losses that was the forerunner of many of the correlations developed later by Klein[2], Agarwal and Larsen[3], Malhotra, Garg and Palit[4] and Garg and Datta[5]. Hottel and Whillier[6] and Bliss[7] derived several flat-plate efficiency factors useful in the design of solar collectors. In the mid 1970s, many new collector designs appeared on the commercial market. A need developed for a standard test procedure to produce data of the type required in process design. In response to this need, the National Bureau of Standards devised a test procedure that was modified by ASHRAE in 1977 (Hill and Kusuda[8] and Hill and Streed[9]). The experiments in support of the development of the ASHRAE 93-77 standard procedure are described by Hill et al.[10]. An analysis of the thermal performance of a flat-plate collector containing a boiling fluid and operating in a thermosiphon mode was published in 1983 by Al-Tamimi and Clark[11]. The validity of the analytical model was confirmed [11] by experimental measurements on a system containing $\mathrm{R}-11$. This analysis has formed the technical basis of the ASHRAE Test Standard 109P for boiling collectors. This work has been extended by Clark[12] to include the generalized thermal performance of boiling flat-plate collectors with saturated exit conditions. The thermal performance of a compound parabolic concentrator (CPC) operating in single and

*Present address: Deparment of Mechanical Engineering, Faculty of Engineering, Ain Shams University, Abbassia, Cairo, Egypt.

†Member, ISES. multiphase flows, including exit superheat is reported by El-Assy[13] and El-Assy and Clark[14].

The objective of the present work is to analyze a flat-plate collector operating under nonboiling, boiling, and superheated conditions. The overall thermal efficiency, $\eta$ is shown to be

$$
\eta=F_{s}\left[\eta_{0}-\frac{U_{L}\left(T_{1}-T_{a}\right)}{I}\right]
$$

where $F_{s}$ is a new generalized heat removal factor and $U_{L}$ is a new overall thermal loss coefficient for a collector operating with multiphase flows, including superheat, $\eta_{0}$ is the optical efficiency of the coverabsorber plate subsystem derived by standard optical procedures as described in [15], $T_{1}$ and $T_{a}$ are the inlet fluid temperature and the ambient temperature, and $I$ is the total incident solar radiation. The analysis includes the thermal modeling of the flat-plate collector and the parameters that identify its behaviour under these single and multiphase conditions are derived.

Although the present analysis is devoted to the performance of the boiling collector itself, the performance of a system incorporating a boiling collector must include the operating characteristics of the condenser, as has been done by Price, Klein, and Beckman[19]. A similar consideration for solar thermal power systems is included in a recent study by El-Assy[13]. Also note that the flow rate per unit collector area $\left(w / A_{c}\right)$ for boiling collectors is much smaller ( $10 \%$ or less) than corresponding values in nonboiling, liquid-cooled collectors owing to the latent heat energy absorption of the coolant in the phase change that occurs during boiling.

\section{THERMAL LOSS COEFFICIENTS, $U_{s B}, U_{B}$, AND $U_{s}$}

The thermal top loss coefficient for each of the nonboiling, boiling, and superheating regions illus- 
trated in Fig. 1. $U_{T A B} . U_{T, B}$, and $U_{T, S}$, respectively, are obtained from Garg and Datta[5] or Klein[2] by urilizing the average absorber plate temperature in each region. The thermal top loss coefficient varies along the absorber plate as a consequence of different plate temperatures associated with each of the regions. The total thermal loss coefficient for the nonboiling region, $U_{N B}$, for the boiling region, $U_{B}$, and for the superheating region, $U_{S}$, are defined as

$$
\begin{aligned}
U_{N B} & =U_{T, V B}+U_{\text {back }}+U_{\text {edge }} \\
U_{B} & =U_{T, B}+U_{\text {back }}+U_{\text {edge }} \\
U_{S} & =U_{T, S}+U_{\text {back }}+U_{\text {edge }}
\end{aligned}
$$

where $U_{\text {back }}$ is the back loss coefficient and $U_{\text {edge }}$ is that for the edges of the collector.

It is recognized that the Klein method[2] for determining the top loss coefficients assumes a surface of uniform temperature. In the present analysis, the top loss coefficients used in each of the regions of flow is that value corresponding to the effective mean surface temperature for time region, a value that can be estimated satisfactorily.

\section{GENERALIZED HEAT REMOVAL FACTOR, $\bar{F}_{5}$, AND GENERALIZED OVERALL THERMAL LOSS COEFFICIENT, $U_{L}$}

For a generalized model of flow in a flat-plate collector, the coolant with subcooled inlet conditions can experience nonboiling, boiling, and superheating conditions during its passage through the channels of the collector. The total useful energy by solar conversion will be written for this process as

$$
q_{u}=q_{u, N B}+q_{u, B}+q_{u, S}
$$

where $q_{u, \backslash B} q_{u, B}$, and $q_{u, S}$ are the useful energy gains in the nonboiling, boiling, and superheating region, as illustrated in Fig. 1.

In the nonboiling region, the rate of increase in the fluid enthalpy in the flow direction is

$$
w^{\prime} c_{p i} \frac{d T}{d z}=F^{\prime}\left[I \eta_{0}-U_{N B}\left(T-T_{a}\right)\right] W
$$

where $w^{\prime}$ is the fluid mass flow rate per tube, $\mathrm{kg} / \mathrm{s}$; $c_{p l}$ is the liquid-phase specific heat, $\mathrm{J} / \mathrm{kg} \mathrm{K}$; $I$ is the total incident solar radiation, $\mathrm{W} / \mathrm{m}^{2}$; and $\mathrm{W}$ is the distance between the tubes. $F^{\prime}$ is the collector efficiency factor for the nonboiling region[15] and is defined as

$$
F^{\prime}=\frac{\frac{1}{U_{N B}}}{W\left\{\frac{1}{U_{N^{N B}}[D+(W-D) F]}+\frac{1}{R_{b}}+\frac{1}{\pi D_{i} h_{l}}\right\}}
$$

where $D$ and $D_{i}$ are the outer and inner tube diameter,

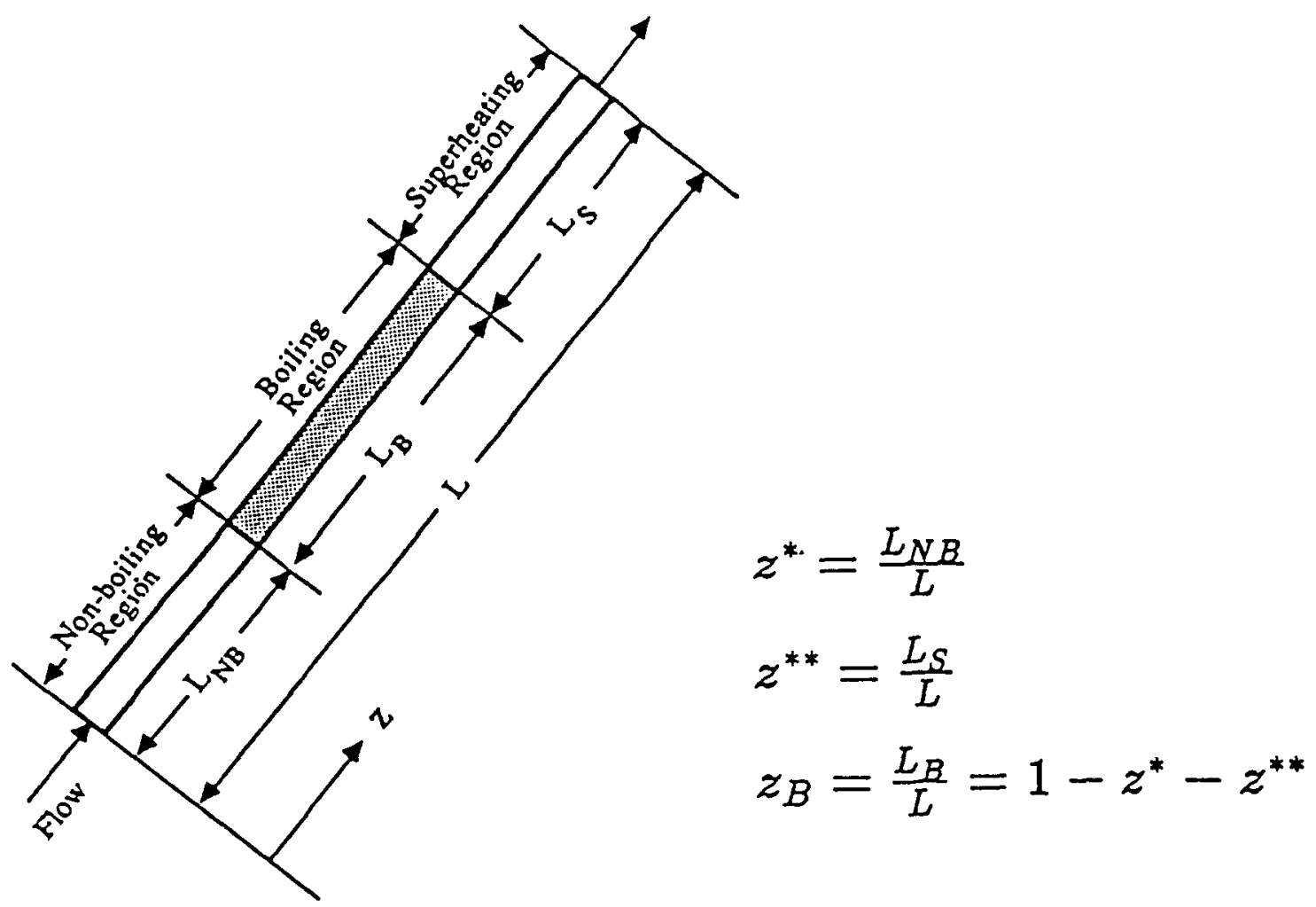

Fig. 1. Single and multiphase flows, including superheat. 


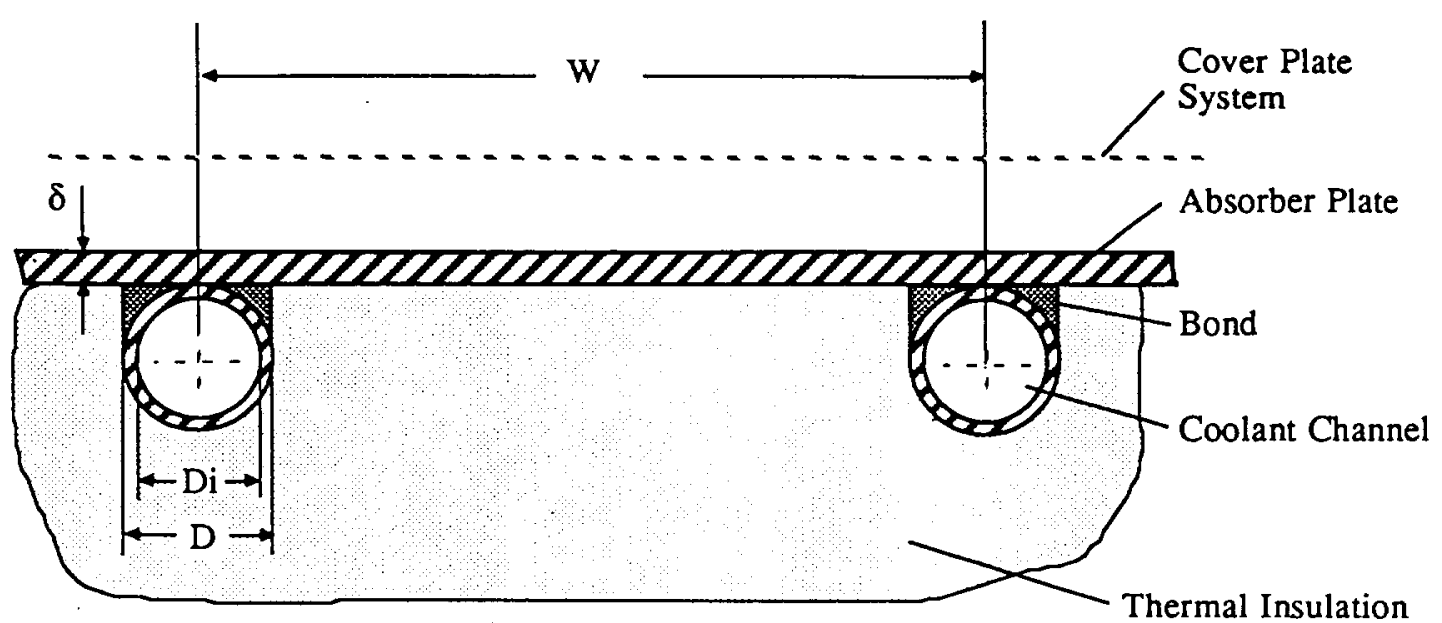

Fig. 2. Cross-section of flat-plate collector.

Fig. 2, $F$ is the fin efficiency given by $F=\{\tan \mathrm{h}[m(W$ - $D) / 2 / m(W-D) / 2\}$ where $m$ is equal to $\sqrt{\left(U_{N B} / k \delta\right)}, k$ is the thermal conductivity of the fin material, $W / \mathrm{m} \mathrm{K}$, and $\delta$ is the thickness of the absorber plate, $R_{b}$ is the bond thermal resistance per unit length and $h_{l}$ is the channel transfer coefficient, $\mathrm{W} / \mathrm{m}^{2} \mathrm{~K}$, for the fluid as given by Brown and Ganvin[16].

Integrating over the nonboiling length $L_{N B}$, gives

$$
\int_{T_{1}}^{T_{\text {sat }}} \frac{d T}{\frac{I_{0}}{U_{N B}}-\left(T-T_{a}\right)}=\int_{0}^{L_{N B}} \frac{U_{N B} F^{\prime} W}{w^{\prime} c_{p l}} d z
$$

or

$$
\frac{I \eta_{0}-U_{\mathrm{NB}}\left(T_{\mathrm{sal}}-T_{a}\right)}{I \eta_{0}-U_{\mathrm{NB}}\left(T_{1}-T_{a}\right)}=e^{-a z^{*}}
$$

where $T_{1}$ is the fluid inlet temperature, $T_{\mathrm{sat}}$ is the saturation temperature, and $z^{*}$ is the dimensionless length, $L_{N B} / L$, Fig. 1, of the nonboiling region as defined by Al-Tamimi and Clark[11]. The parameter $a$ is the dimensionless capacitance rate for nonboiling conditions defined as

$$
a=\frac{F^{\prime} U_{N B}}{\left(w / A_{c}\right) c_{p l}}
$$

where $A_{c}$ is the collector area, $\mathrm{m}^{2} . q_{u, N B}$ can also be written as

$$
\begin{aligned}
q_{u, n B} & =w c_{p l}\left(T_{\text {sat }}-T_{1}\right) \\
& =w c_{p l}\left[\left(T_{\text {sat }}-T_{a}\right)-\left(T_{1}-T_{a}\right)\right]
\end{aligned}
$$

Substituting eqn (9) into eqn (11) and rearranging gives

$$
q_{u, N B}=\frac{F^{\prime}}{a}\left(1-e^{-a z^{*}}\right) A_{c}\left[I \eta_{0}-U_{N B}\left(T_{1}-T_{a}\right)\right]
$$

In the boiling region, the net thermal energy transfered to the fluid over the differential channel length $d z$, which results in an enthalpy increase of the fluid, is written as

$$
d q_{u, B}=F_{B}^{\prime}\left[I \eta_{0}-U_{B}\left(T_{\mathrm{sat}}-T_{a}\right)\right] n W d z
$$

where $n$ is the number of tubes in the collector and $F_{B}^{\prime}$ is the collector efficiency factor for the boiling region defined in the same way as $F^{\prime}$, eqn (7). except that the total loss coefficient is $U_{B}$ and the channel heat transfer coefficient, $h_{b}$, corresponds to that for flow boiling and is determined using the McNelly model[17]. $F_{B}^{\prime}$ is therefore,

$$
F_{B}^{\prime}=\frac{\frac{1}{U_{B}}}{W\left[\frac{1}{U_{B}[D+(W-D) F]}+\frac{1}{R_{b}}+\frac{1}{\pi D_{i} h_{b}}\right]}
$$

Because the temperature of the two-phase fluid, $T_{\text {sat }}$, in the boiling channel is essentially constant over the boiling length, eqn (13) may be integrated over the boiling length $z_{B}=1-z^{*}-z^{* *}$, for a change in state of the coolant from that of a saturated liquid to a saturated vapor. Hence, in flows for which a superheated exit state $\left(z^{* *} \geq 0.0\right)$ exists $q_{u B}$ becomes

$$
q_{u . B}=F_{B}^{\prime} A_{c}\left(1-z^{*}-z^{* *}\right)\left[I \eta_{0}-U_{B}\left(\mathrm{~T}_{\mathrm{sat}}-T_{a}\right)\right.
$$

As will be seen in this development, it is convenient and useful to express eqn (15) in terms of the temperature difference $\left(T_{1}-T_{a}\right)$, as in eqn (12), rather than $\left(T_{\text {sat }}-T_{a}\right)$. To do this, eqn (13) is integrated for a reference nonboiling condition in a manner similar to eqn (8), except that the thermal loss coefficient will be that corresponding to the boiling condition, $U_{B}$. Accordingly, eqn (13) becomes 


$$
\int_{T_{1}}^{T_{\mathrm{sat}}} \frac{d T}{\frac{I_{0}}{U_{B}}-\left(T-T_{a}\right)}=\int_{0}^{L_{\mathrm{s} B}} \frac{U_{B} F_{b}^{\prime} W}{w^{\prime} c_{p l}} d z
$$

or

$$
\frac{I \eta_{0}-U_{B}\left(T_{\text {sat }}-T_{a}\right)}{I \eta_{0}-U_{B}\left(T_{1}-T_{a}\right)}=e^{-a_{b} z^{*}}
$$

where $a_{b}$ is defined as

$$
a_{b}=\frac{F_{b}^{\prime} U_{B}}{\left(w / A_{c}\right) c_{p l}}=a \frac{F_{b}^{\prime}}{F^{\prime}} \frac{U_{B}}{U_{\mathrm{v} B}}
$$

and $F_{b}^{\prime}$ is defined for this reference nonboiling condition as

$$
F_{b}^{\prime}=\frac{\frac{1}{U_{B}}}{W\left[\frac{1}{U_{B}[D+(W-D) F]}+\frac{1}{R_{b}}+\frac{1}{\pi D_{i} h_{l}}\right]}
$$

Hence, $q_{u, B}$ is written as

$$
\begin{aligned}
q_{u, B}= & F_{B}^{\prime} A_{c}\left(1-z^{*}-z^{* *}\right) \\
& {\left[I \eta_{0}-U_{B}\left(T_{1}-T_{a}\right)\right] e^{-a_{b}=*} }
\end{aligned}
$$

where $z^{* *}$ is the dimensionless superheating region length defined as $L_{s} / L$.

The useful energy in the boiling region, $q_{u, B}$, may also be expressed in terms of the latent heat of vaporization, $h_{f g}$, and the exit quality from the boiling region, $x_{B}$, as

$$
q_{u, B}=w x_{B} h_{f g}
$$

where $x_{B}=1.0$ for $z^{* *} \geq 0.0$ and $x_{B} \leq 1.0$ for $z^{* *}$ $=0.0$. Thus, for superheated exit channel conditions, corresponding to $z^{* *} \geq 0.0$ and $x_{B}=1.0$,

$$
\begin{aligned}
w h_{f g}= & F_{B}^{\prime} A_{c}\left(1-z^{*}-z^{* *}\right) \\
& {\left[I \eta_{0}-U_{B}\left(T_{1}-T_{a}\right)\right] e^{-a_{b}} z^{*} }
\end{aligned}
$$

or

$$
\begin{aligned}
w h_{f g}= & F_{B}^{\prime} A_{c}\left(1-z^{*}-z^{* *}\right) \\
& {\left[I \eta_{0}-U_{B}\left(T_{\text {sat }}-T_{a}\right)\right] }
\end{aligned}
$$

For the case of a saturated, two-phase, condition at the channel exit (i.e., $z^{* *}=0.0$ and the temperature of the exit fluid mixture equal to $T_{\text {sat }}$ ), the exit quality $x_{B} \leq 1.0$ and eqn (23) is rewritten as

$$
w x_{B} h_{f g}=F_{B}^{\prime} A_{c}\left(1-z^{*}\right)\left[I \eta_{0}-U_{B}\left(T_{\text {sat }}-T_{a}\right)\right]
$$

or

$$
\begin{aligned}
w x_{B} h_{f g}= & F_{B}^{\prime} A_{c}\left(1-z^{*}\right) \\
& {\left[I \eta_{0}-U_{B}\left(T_{1}-T_{a}\right)\right] e^{-a_{b} z^{*}} }
\end{aligned}
$$

The combination of eqns (25) and (12) represents the conditions studied by Al-Tamimi and Clark[11] but with a distinction introduced here between the thermal loss coefficients $U_{N B}$ and $U_{B}$.

In the superheated region, the increase in the fluid enthalpy is equal to $d q_{u . s}$ and is written as

$$
\begin{aligned}
d q_{u . S} & =F_{s}^{\prime}\left[I \eta_{0}-U_{S}\left(T-T_{a}\right)\right] n W d z \\
& ={ }^{\prime} c_{p g} d T
\end{aligned}
$$

where $c_{p g}$ is the specific heat of the gaseous phase, $\mathrm{J} / \mathrm{kg} \mathrm{K}$ and $F_{S}^{\prime}$ is the collector efficiency factor for the superheated region given as

$F_{S}^{\prime}=\frac{\frac{1}{U_{S}}}{W\left[\frac{1}{U_{S}[D+(W-D) F]}+\frac{1}{R_{b}}+\frac{1}{\pi D_{i} h_{s}}\right]}$

$U_{S}$ is the thermal loss coefficient for the superheated region, $w / \mathrm{m}^{2} \mathrm{~K}$ and $h_{s}$ is the channel heat transfer coefficient, $w / \mathrm{m}^{2} \mathrm{~K}$, for the superheated vapor, as given by Brown and Ganvin[16]. Integrating eqn (26) over the superheated region, Fig. 1, yields

$$
\int_{T \mathrm{sat}}^{T_{s}} \frac{d T}{\frac{I \eta_{0}}{U_{S}}-\left(T-T_{a}\right)}=\int_{L_{\mathrm{v} \mathrm{B}}+L_{B}}^{L} \frac{U_{S} F_{S}^{\prime} W}{w^{\prime} c_{p g}} d z
$$

or

$$
\frac{I \eta_{0}-U_{S}\left(T_{2 s}-T_{a}\right)}{I \eta_{0}-U_{S}\left(T_{\text {sat }}-T_{a}\right)}=\exp -\frac{U_{s} F_{s}^{\prime} W L_{S}}{w^{\prime} c_{p g}}
$$

where $T_{2 s}$ is the exit temperature of the superheated vapor, $K$. A parameter similar to $a$ for the nonboiling region may be defined for the superheated region as

$$
a_{S}=\frac{F_{S}^{\prime} U_{S}}{\left(w / A_{c}\right) c_{p g}}=a \frac{F_{S}^{\prime}}{F^{\prime}} \frac{U_{S}}{U_{N B}} \frac{c_{p l}}{c_{p g}}
$$

which can be introduced into the exponential term in eqn (29) to give

$$
\frac{I \eta_{0}-U_{S}\left(T_{2 s}-T_{a}\right)}{I \eta_{0}-U_{S}\left(T_{\text {sat }}-T_{a}\right)}=e^{-a_{5} z^{* *}}
$$

The useful energy gain in the superheated region, $q_{u, s}$ may also be written as

$$
q_{u, S}=w c_{p g}\left(T_{2 s}-T_{\text {sat }}\right)
$$


or, alternatively

$$
\begin{aligned}
q_{u . S}=\frac{w c_{p q}}{U_{S}}\left\{\left[I \eta_{0}-\right.\right. & \left.U_{S}\left(T_{\mathrm{sat}}-T_{a}\right)\right] \\
& \left.-\left[I \eta_{0}-U_{S}\left(T_{2 s}-T_{a}\right)\right]\right\}
\end{aligned}
$$

Substituting eqn (31) into eqn (33) and rearranging. yields

$$
q_{u, S}=\frac{F_{S}^{\prime}}{a_{S}}\left(1-e^{-a_{S} z * *}\right) A_{c}\left[I \eta_{0}-U_{S}\left(T_{\mathrm{sat}}-T_{a}\right)\right]
$$

which enables the definition of the heat removal factor for superheated conditions, $F_{R S}$ to be

$$
F_{R S}=\frac{F_{S}^{\prime}}{a_{S}}\left(1-e^{-a_{S}=* *}\right)
$$

Equation (26) may be treated in the same manner as eqn (13) in order to relate $q_{u . s}$ to the temperature difference $\left(T_{1}-T_{a}\right)$ rather than $\left(T_{\text {sat }}-T_{a}\right)$. Hence, by considering a similar reference nonboiling condition, eqn (26) is integrated as

$$
\int_{T_{1}}^{T_{s a 1}} \frac{d T}{\frac{I \eta_{0}}{U_{S}}-\left(T-T_{a}\right)}=\int_{0}^{L_{N B}} \frac{U_{s} F_{s}^{\prime} W}{w^{\prime} c_{p l}} d z
$$

or,

$$
\frac{I \eta_{0}-U_{S}\left(T_{\mathrm{sat}}-T_{a}\right)}{I \eta_{0}-U_{S}\left(T_{1}-T_{a}\right)}=e^{-u_{s}=*}
$$

where $a_{s}$ is defined as

$$
a_{s}=\frac{F_{s}^{\prime} U_{s}}{\left(w / A_{c}\right) c_{p l}}=a \frac{F_{s}^{\prime}}{F^{\prime}} \frac{U_{s}}{U_{N B}}
$$

and $F_{s}^{\prime}$ defined as

$$
F_{s}^{\prime}=\frac{\frac{1}{U_{s}}}{W\left[\frac{1}{U_{s}[D+(W-D) F]}+\frac{1}{R_{b}}+\frac{1}{\pi D_{i} h_{l}}\right]}
$$

Introducing eqn (37) into (34) yields

$$
q_{u, S}=\frac{F_{S}^{\prime}}{a_{S}}\left(1-e^{-u_{S} \mathbf{z}^{* *}}\right) A_{\mathrm{c}}\left[I \eta_{0}-U_{S}\left(T_{1}-T_{a}\right)\right] e^{-u_{\mathrm{r}}: *}
$$

The total useful energy collected by a flat-plate under nonboiling. boiling, and superheated exit fluid conditions is found by combining the results in eqns (12), (20), and (40) into eqn (5) to give

$$
\begin{aligned}
q_{u}= & F_{R} A_{c}\left[\frac{1-e^{-u z^{*}}}{1-e^{-a}}\right. \\
& +\frac{\left(1-z^{*}-z^{* *}\right) e^{a_{b} *^{*}}}{F_{R} / F_{s}^{\prime}} \\
& \left.+\frac{\left(1-e^{-a_{S} z^{* *}}\right) e^{-a_{s} z^{*}}}{a_{S} F_{R} / F_{S}^{\prime}}\right] \\
& \times\left[I \eta_{0}-U_{L}\left(T_{1}-T_{u}\right)\right]
\end{aligned}
$$

where $F_{R}$ is the heat removal factor for a nonboiling collector having the same value of $a$ and $F^{\prime}$ as the boiling collector with a superheated exit state and is defined [15] as

$$
F_{R}=\frac{F^{\prime}}{a}\left(1-e^{-a}\right)=F^{\prime \prime} F^{\prime}
$$

where $F^{\prime \prime}$ is the collector flow factor. The first bracketed term in eqn $(41)$ may be defined as

$$
\begin{aligned}
F_{S}= & \frac{1-e^{-a z^{*}}}{1-e^{-a}}+\frac{\left(1-z^{*}-z^{* *}\right) e^{-a_{j} z^{*}}}{F_{R} / F_{B}^{\prime}} \\
& +\frac{\left(1-e^{-a_{S} z^{* *}}\right) e^{-a_{s} z^{* *}}}{a_{S} F_{R} / F_{S}^{\prime}}
\end{aligned}
$$

Accordingly, from eqns (41) and (42), a new generalized heat removal factor, $\mathscr{F}_{s}$, describing the performance of a flat-plate collector in which the states of flow consisting of subcooled, nonboiling. boiling, and superheated conditions may simultaneously exist along the coolant channels is defined as

$$
F_{S}=F_{R} F_{S}
$$

The overall thermal loss coefficient, $U_{L}$, in egn (41) may be shown to be a weighted average of the thermal loss coefficients $U_{\mathrm{N} B}, U_{B}$, and $U_{S}$ as

$$
U_{L}=\frac{\left[\frac{F^{\prime}}{a}\left(1-e^{-a z^{*}}\right)\right] U_{N B}+\left[F_{B}^{\prime}\left(1-z^{*}-z^{* *}\right) e^{-a_{b} z^{*}}\right] U_{B}+\left[\frac{F_{S}^{\prime}}{a_{S}}\left(1-e^{-a_{S} z^{* *}}\right) e^{-a_{S} z^{* *}}\right] U_{S}}{\frac{F^{\prime}}{a}\left(1-e^{-a z^{*}}\right)+F_{B}^{\prime}\left(1-z^{*}-z^{* *}\right) e^{-a_{b} z^{*}}+\frac{F_{S}^{\prime}}{a_{S}}\left(1-e^{-a_{S} z^{* *}}\right) e^{-a_{s} z^{*}}}
$$


or, as a functional relationship, as

$$
U_{L}=f_{1}\left(a, \frac{F_{B}^{\prime}}{F^{\prime}}, \frac{F_{S}^{\prime}}{F^{\prime}}, \frac{F_{b}^{\prime}}{F^{\prime}}, \frac{F_{s}^{\prime}}{F^{\prime}}, U_{\mathrm{NB}}, \frac{U_{B}}{U_{\mathrm{NB}}}, \frac{U_{S}}{U_{\mathrm{NB}}}, z^{*}, z^{* *}, \frac{c_{p l}}{c_{p g}}\right)
$$

Hence, $q_{u}$ is written as:

$$
q_{u}=\mathscr{F}_{S} A_{c}\left[I \eta_{0}-U_{L}\left(T_{1}-T_{a}\right)\right]
$$

from which the thermal conversion efficiency, $\eta$, becomes

$$
\eta=\mathscr{F}_{s}\left[\eta_{0}-\frac{U_{L}\left(T_{1}-T_{a}\right)}{I}\right]
$$

In this result, the optical efficiency $\eta_{0}$ is that given by Duffie and Beckman[15] as

$$
\eta_{0}=(\alpha \tau)_{e}=\frac{\alpha \tau}{1-\rho_{d}(1-\alpha)}
$$

where $\alpha$ is the absorptivity of the absorber plate, $\tau$ is the transmissivity of the cover system and $\rho_{d}$ is the diffuse reflectivity of the absorber plate, all to solar radiation.

The Generalized Heat Removal Factor $\mathscr{F}_{S}$ is an extension of the Heat Removal Factor $\mathscr{F}_{R}$ developed by Al-Tamimi and Clark[11] for boiling flat-plate collectors having saturated discharge states. The present extension includes the effect of superheated discharge states. The functional dependence of $F_{s}$ on the several operational variables and parameters is found from eqns (42) and (43) to be and

$$
z^{* *}=\frac{1}{a_{S}} \ln \frac{\eta_{T_{\mathrm{sat}}}}{\eta_{T_{2 s}}}
$$

where $\eta_{T_{1}}, \eta_{T_{\text {st }}}$ and $\eta_{T_{23}}$ are the efficiencies of the single-phase (nonboiling) collector having inlet temperatures $T_{1}, T_{\text {sat }}$, and $T_{2 s}$, respectively. At this point, it is necessary to know the operating pressure of the collector in order to determine $T_{\text {sat }}$. This will depend on the operating conditions of the complete system but may be reasonably estimated from the thermal state of the system component feeding the collector. For example, in a water heating application, this could be the preheat tank temperature, and in a power producing system it would be the temperature of the condenser coolant, probably the ambient air temperature or that of ground water.

\section{DISCUSSION}

An evaluation of the significance of these results rests mainly on an examination of the influence of dimensionless lengths $z^{*}$ and $z^{* *}$ and other parameters on the new Generalized Heat Removal Factor. $\widetilde{F}_{S}$, the Overall Thermal Loss Coefficient, $U_{L}$, and the thermal conversion efficiency, $\eta$. This evaluation is given in reference to Figs. 3, 4, 5, and 6.

$$
\mathscr{F}_{S}=f_{2}\left(a, F^{\prime}, \frac{F_{B}^{\prime}}{F^{\prime}}, \frac{F_{S}^{\prime}}{F^{\prime}}, \frac{F_{b}^{\prime}}{F^{\prime}}, \frac{F_{s}^{\prime}}{F^{\prime}}, \frac{U_{B}}{U_{N B}}, \frac{U_{S}}{U_{v B}}, z^{*}, z^{* *}, \frac{c_{p l}}{c_{p g}}\right)
$$

For boiling flat-plate collectors having saturated discharge states, the heat removal factor $\mathscr{F}_{R}$, developed by Al-Tamimi and Clark[11] and Clark[12], is represented as

$$
\mathscr{F}_{R}=f\left(a, F^{\prime}, \frac{F_{B}^{\prime}}{F^{\prime}}, z^{*}\right)
$$

The greater generalization in process description provided by $F_{S}$ is evident in the comparison of eqns (50) and (51). The parameters $z^{*}$ and $z^{* *}$ in the Generalized Heat Removal Factor $\mathcal{F}_{S}$ and the Generalized Overall Thermal Loss Coefficient $U_{L}$ are determined from eqns (9) and (31) as

$$
z^{*}=\frac{1}{a} \ln \frac{\eta_{T_{1}}}{\eta_{T_{\mathrm{sat}}}}
$$

The dimensionless lengths $z^{*}$ and $z^{* *}$ are each established by the operating conditions, as indicated by eqns (52) and (53). While the relationships between $\mathscr{F}_{S}, U_{L}$, and $\eta$ and $z^{*}$ and $z^{* *}$ are implicit, the values of $z^{*}$ and $z^{* *}$ are fixed in terms of the operating parameters. However, due to their fairly complex mathematical form, it is difficult to perform an algebraic evaluation of the functions $F_{5}, U_{L}$, and $\eta$. Instead, their functional relationship with respect to $z^{*}$ and $z^{* *}$ will be determined by computer simulation for a set of fixed, but normal, operating conditions. To accomplish this, $\mathscr{F}_{S}, U_{L}$, and $\eta$ have been computed using $\mathrm{R}-11$ as the coolant fluid at a flow rate per unit collector area, $\left(w / A_{c}\right)$, of $0.002 \mathrm{~kg} / \mathrm{sm}^{2}$ at a working pressure of $0.7 \mathrm{MPa}$. The emissivity of the absorber plate is 0.1 . For the determination of representative absorber plate thermal states, the solar intensity used in the simulation is $1000 \mathrm{~W} / \mathrm{m}^{2}$ and $T_{1}=T_{a}=20^{\circ} \mathrm{C}$. 


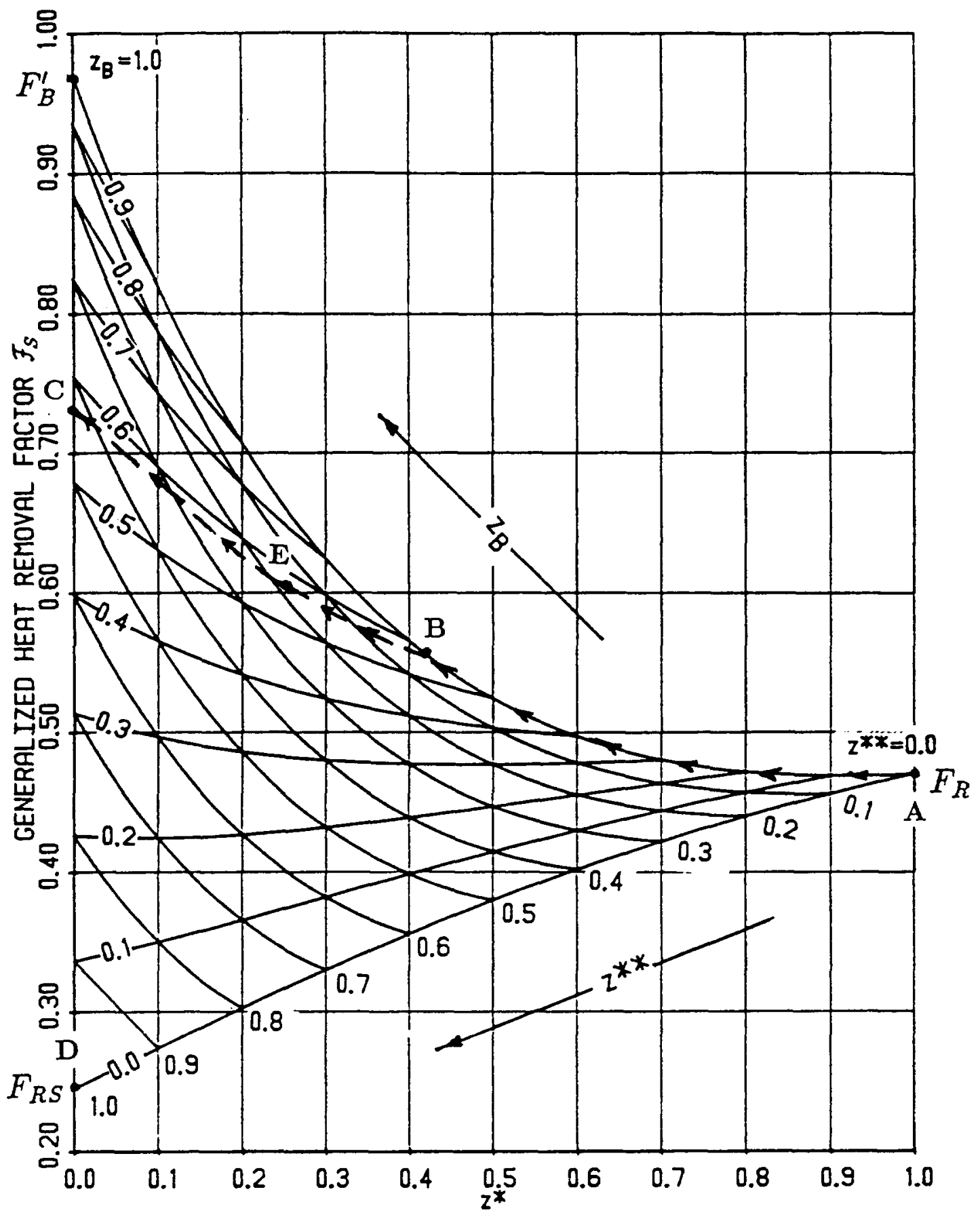

Fig. 3. Generalized heat removal factor $F_{s}$ for $\mathrm{R}-11, w / A_{c}=0.002 \mathrm{~kg} / \mathrm{sm}^{2}, p=0.70 \mathrm{MPa}, \epsilon_{a}=0 . \mathrm{I}$, and thermal loss coefficients $U_{N B}, U_{B}$, and $U_{S}$ of $3.0,3.5$, and $5.0 \mathrm{~W} / \mathrm{m}^{2} \mathrm{~K}$, respectively.

Accordingly, although the results of this simulation shown in Fig. 3 for $\mathscr{F}_{S}$ and in Fig. 4 for $U_{L}$ correspond specifically to a collector operating at $\left(T_{1}-\right.$ $T_{a}$ )/I equal to zero, the results obtained may be applied to other conditions, as will be shown. Simulation for finite values of $\left(T_{1}-T_{a}\right) / l$ are given for $\eta$ in Figs. 5 and 6 and summarized in Table 1 . At the working pressure of $0.7 \mathrm{MPa}$, the saturation temperature of $\mathrm{R}-11$ is $92.4^{\circ} \mathrm{C}$ and the average effective absorber plate temperatures at $I=1000 \mathrm{~W} / \mathrm{m}^{2}, T_{1}=$
$T_{a}=20^{\circ} \mathrm{C}$ for the nonboiling, boiling, and superheating regions are approximately 75,100 , and $200^{\circ} \mathrm{C}$, as determined by the thermal analysis. However, it can be shown that for a fixed working pressure, the average effective absorber plate temperature and, hence, the values of $U_{N B}$ and $U_{B}$ for the nonboiling and boiling regions are little affected by reasonably wide variations in $I, T_{1}$, and $T_{a}$ from the values chosen for this simulation. The average effective absorber plate temperature in the superheated region is 


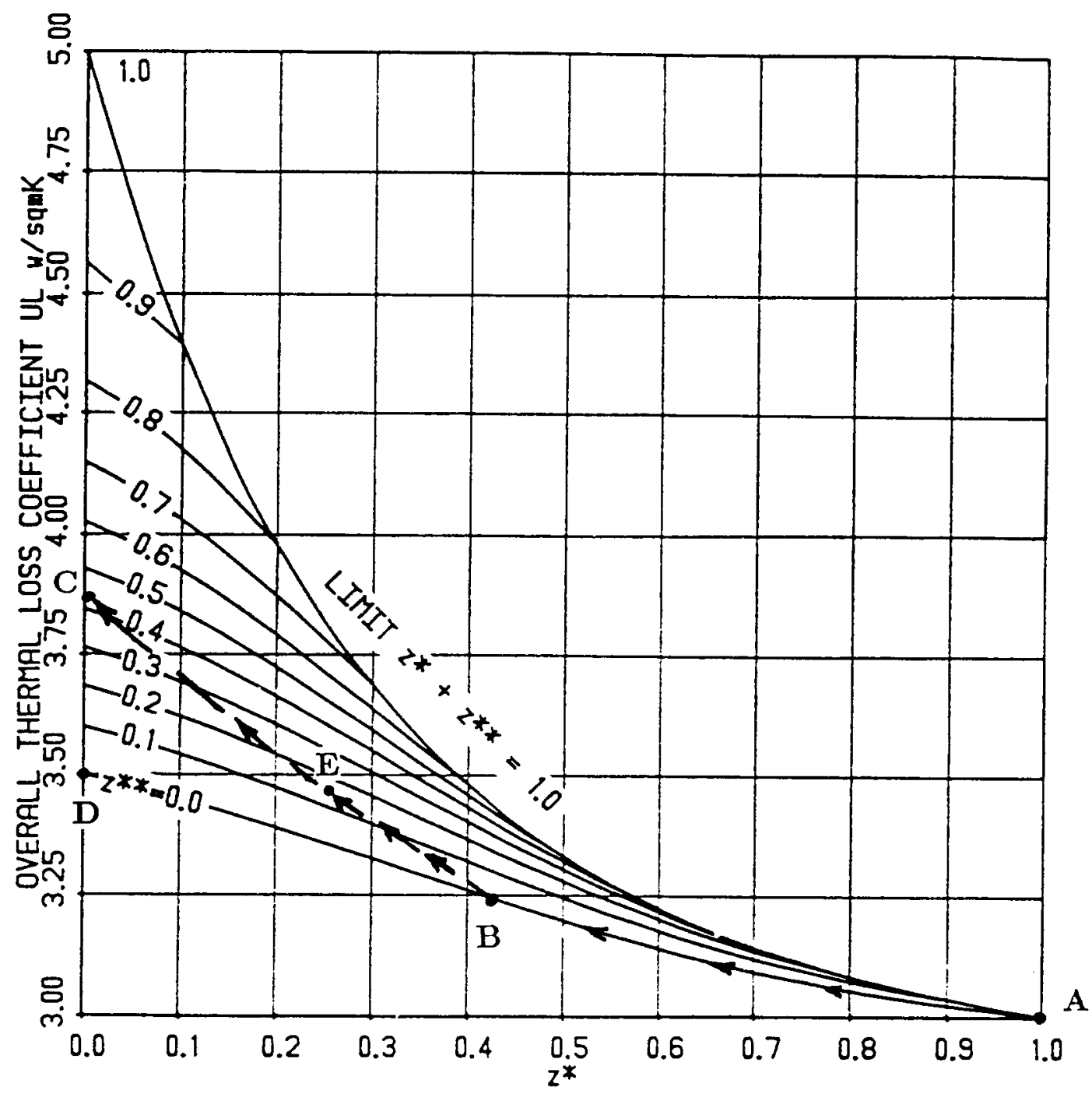

Fig. 4. Overall thermal loss coefficient $U_{l}$ for $U_{B}=3.5$, and $U_{S}=5.0 \mathrm{~W} / \mathrm{m}^{2} \mathrm{~K}$. Other conditions correspond to those in Fig. 3.

somewhat more affected by variations in $l, T_{1}$, and $T_{a}$ but fairly wide variations in this temperature do not translate into large changes in the value of $U_{S}$. For these reasons, the values of $U_{N B}, U_{B}$, and $U_{S}$ of $3.0,3.5$, and $5.0 \mathrm{~W} / \mathrm{m}^{2} \mathrm{~K}$, respectively, are taken to be representative over a range of different operating conditions of $I, T_{1}$, and $T_{a}$.

For this representation, $\mathscr{F}_{S}$ is shown to be determined by the parameters $z^{*}, z^{* *}$, and $z_{B}$, which is (1 $\left.-z^{*}-z^{* *}\right)$. The dimensionless superheated channel length, $z^{* *}$, has a possible range between 0.0 and 1.0 although, as a practical matter, it would be expected normally to be less than 0.4 . For greater values, the exit superheat would be very large, probably exceeding $200^{\circ} \mathrm{C}$ for the conditions stated, and thus produce an unacceptably poor conversion efficiency for most purposes. Certain operating limits may be identified for $\mathscr{F}_{s}$. When $z^{*}=1.0$, the flat-plate collector would be operating in a fully nonboiling mode (point A, Fig. 3) in subcooled, single-phase liquid flow. Under normal operating conditions, as the incident solar radiation, $l$, is increased or as the inlet subcooling, $T_{\text {sat }}-T_{1}$, is decreased, there will be a condition reached at which a saturated liquid state will exist, and thus boiling be incipient, at the exit of the coolant tubes. As the boiling process develops by further increases in $I$ or decreases in inlet subcooling, the quality of the saturated liquid-vapor mixture at the exit of the coolant tubes will increase, which produces an increase in $z_{B}$, the fractional length of the channel under boiling and a corresponding decrease in $z^{*}$. This is described by a path similar to that from A to B. Fig. 3, along the locus $z^{* *}=0.0$. since saturated liquid-vapor states exist at the exit of the coolant tubes. $F_{s}$ is increased during this process. There will be some point (B, Fig. 3) at which the exit state becomes that of a saturated vapor $\left(x_{B}=\right.$ 1.0 ), and any further increases in the incident solar radiation, $I$, or decreases in the inlet subcooling will cause the exit state to become that of a superheated 


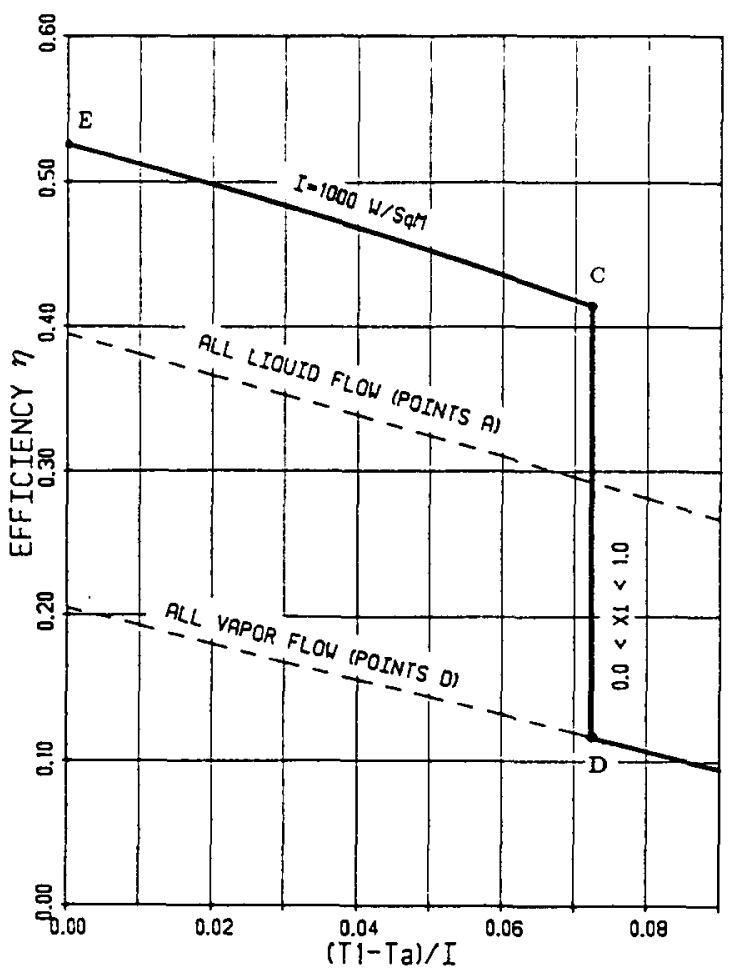

Fig. 5. The flat-plate thermal efficiency at constant $I=$ $1000 \mathrm{~W} / \mathrm{m}^{2}$ (point $\mathrm{C}: z^{*}=0.0, x_{i}=0.0$, and $z^{* *}=0.50$; point $\left.\mathrm{D}: z^{* *}=1.0, x_{i}=1.0\right)$ as a function of $\left(T_{1}-\right.$ $\left.T_{\mathrm{a}}\right) / /$. vapor. The subsequent values of $\widetilde{F}_{s}$ corresponding to these superheated exit states (and subcooled liquid inlet states) are shown as a path similar to that from $\mathrm{B}$ to $\mathrm{E}$ to $\mathrm{C}$. Fig. 3 (see also Table $I$ for $I=1000$ $\mathrm{W} / \mathrm{m}^{2}$ ), with a consequent increase in $\mathscr{F}_{S}$, as shown. However, the thermal efficiency will decrease with increases in the exit superheat as a result of a proportional increase in the thermal losses even with the increase in $F_{5}$, as will be shown. The limit of this process would be the value of $\mathscr{F}_{s}$ corresponding to the point $C$, with $z^{*}=0.0$, which describes a saturated liquid inlet state with a fully boiling condition existing from the inlet, a superheated length $z^{* *}$ of 0.419 , and a boiling length $z_{B}$ of 0.581 . A large number of other states of course are possible, each depending on the specific operating conditions and circumstances. These states can be identified using eqns (41) through (53) once the operating conditions are established.

Certain other limits for $\mathscr{F}_{S}$ may be discussed. For operating conditions having subcooled liquid inlet states and saturated liquid-vapor exit states (i.e., 0 $\leq z^{*} \leq 1.0$ ), the values of $\mathscr{F}_{s}$ all fall along the upper curve of Fig. 3 corresponding to $z^{* *}=0.0$. These are the conditions identified by Al-Tamimi and Clark[11], Clark[12], and El-Assay and Clark[18]. For a fully boiling condition, $z^{*}=0.0$, the maximum possible value of $\widetilde{F}_{S}$ is $F_{B}^{\prime}$, which corresponds to flows having saturated (liquid) inlet and saturated (liquidvapor) exit states. The general conditions, however,

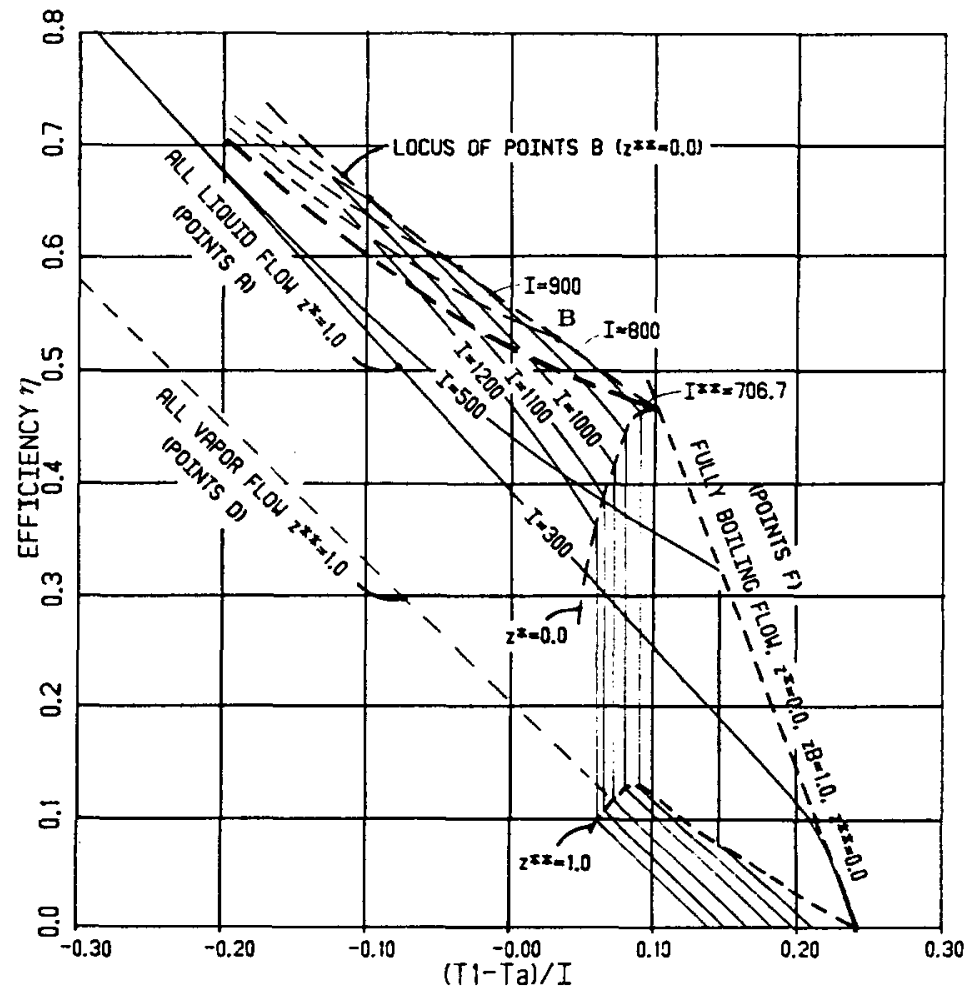

Fig. 6. The thermal efficiency for various incident solar radiation intensities, $l, \mathrm{~W} / \mathrm{m}^{2}$, as a function of $\left(T_{1}-T_{a}\right) / l$, including results for all liquid and all vapor flows. Data are summarized in Table 1 . For $I \leq I^{* *}$, exit state is never superheated; for $I \geq I^{* *}$, exit state is always superheated. 
Table 1. Flat-plate collector parameters for the influence of inlet subcooling and incident solar radiation on the thermal efficiency, as shown in Figs. 3 and $6, w / A_{c}=0.002 \mathrm{~kg} / \mathrm{sm}^{2}, \eta_{0}=0.841, T_{u}=20^{\circ} \mathrm{C}$ $a=F^{\prime} U_{v B} /\left(w / A_{i}\right) c_{p l}=1.446$ and $F_{R}$ and $\left(1-e^{-\mu}\right)=0.469$

\begin{tabular}{|c|c|c|c|c|c|c|c|c|c|}
\hline \multicolumn{10}{|c|}{$I=300 \mathrm{w} / \mathrm{m}^{2}$} \\
\hline \multirow{2}{*}{\multicolumn{2}{|c|}{$\begin{array}{l}F^{\prime}=0.887 \\
a=1.446\end{array}$}} & \multirow{2}{*}{$\begin{array}{l}F_{B}^{\prime}=0.968 \\
a_{b}=1.657\end{array}$} & \multicolumn{2}{|c|}{$F_{b}^{\prime}=0.871$} & \multicolumn{2}{|c|}{$F_{S}^{\prime}=0.750$} & \multicolumn{3}{|c|}{$F_{s}^{\prime}=0.856$} \\
\hline & & & & 2.309 & $a_{s}=1$. & & & & \\
\hline$T_{1}$ & $\frac{T_{1}-T_{a}}{I}$ & $z^{*}$ & $z_{B}$ & $z^{* *}$ & $\mathcal{F}_{S}$ & $U_{L}$ & $\mp_{S} \eta_{0}$ & $\xi_{S} U_{L}$ & $\eta$ \\
\hline-120.0 & -.467 & 1.000 & 0.0 & 0.0 & 0.469 & 3.000 & 0.394 & 1.407 & 1.050 \\
\hline & -.433 & 1.000 & 0.0 & 0.0 & 0.469 & 3.000 & 0.394 & 1.407 & 1.003 \\
\hline-100.0 & -.400 & 1.000 & 0.0 & 0.0 & 0.469 & 3.000 & 0.394 & 1.407 & 0.957 \\
\hline-90.0 & -.367 & 1.000 & 0.0 & 0.0 & 0.469 & 3.000 & 0.394 & 1.407 & 0.910 \\
\hline-80.0 & -.333 & 1.000 & 0.0 & 0.0 & 0.469 & 3.000 & 0.394 & 1.407 & 0.863 \\
\hline 0.0 & -.300 & 1.000 & 0.0 & 0. & 0.4 & 3.000 & 0.9 & & 0.816 \\
\hline-60.0 & -.267 & 1.000 & 0.0 & 0.0 & 0.469 & 3.000 & 0.394 & 1.407 & 0.769 \\
\hline-50.0 & -.233 & 1.000 & 0.0 & 0.0 & 0.469 & 3.000 & 0.394 & 1.407 & 0.722 \\
\hline-40.0 & -.200 & 1.000 & 0.0 & 0.0 & 0.469 & 3.000 & 0.394 & 1.407 & 0.675 \\
\hline-30.0 & -.167 & 1.000 & 0.0 & 0.8 & 0.4 & 3.000 & 0.394 & 1.6 & 0.628 \\
\hline-20.0 & -.133 & 1.000 & 0.0 & 0.0 & 0.469 & 3.000 & 0.394 & 1.407 & 0.581 \\
\hline-10.0 & -.100 & 1.000 & 0.0 & 0.0 & 0.469 & 3.000 & 0.394 & 1.407 & 0.535 \\
\hline 0.0 & -.067 & 1.000 & 0.0 & 0.0 & 0.469 & 3.000 & 0.394 & 1.4 & 0.488 \\
\hline 10.0 & -.033 & 1.000 & 0.0 & 0.0 & 0.469 & 3.000 & 0.394 & 1.407 & 0.441 \\
\hline 20.0 & 0.0 & 1.000 & 0.0 & 0.0 & 0.469 & 3.000 & 0.394 & 1.407 & 0.394 \\
\hline 30.0 & 0.033 & 1.000 & 0.0 & 0. & 0.469 & 3.000 & 0.394 & 1.4 & 0.347 \\
\hline 40.0 & 0.067 & 1.000 & 0.0 & 0.0 & 0.469 & 3.000 & 0.394 & 1.407 & 0.300 \\
\hline 50.0 & 0.100 & 1.000 & 0.0 & 0.0 & 0.469 & 3.000 & 0.394 & 1.407 & 0.253 \\
\hline 60.0 & 0.133 & 1.000 & 0.0 & 0.8 & 0.469 & 3.000 & 0.394 & 1.407 & 0.206 \\
\hline 70.0 & 0.167 & 1.000 & 0.0 & 0. & 0.469 & 3.000 & 0.394 & & 0.159 \\
\hline 80.0 & 0.200 & 1.000 & 0.0 & 0.0 & 0.469 & 3.000 & 0.394 & 1.407 & 0.113 \\
\hline 92.4 & 0.241 & 0.0 & 1.000 & 0.0 & 0.968 & & 0.813 & 3.3 & -.005 \\
\hline 92.4 & 0.241 & 0. & 0.0 & 1.000 & 0.293 & 4.0 & 0.246 & 1.171 & -.037 \\
\hline 100.0 & 0.267 & 0.0 & 0.0 & 1.000 & 0.293 & 4.000 & 0.246 & 1.171 & -.066 \\
\hline 110.0 & 0.300 & 0.0 & 0.0 & 1.000 & 0.293 & 4.000 & 0.246 & 1.171 & -.105 \\
\hline
\end{tabular}

$I=500 w / m^{2}$

$$
\begin{array}{llll}
F^{\prime}=0.887 & F_{B}^{\prime}=0.968 & F_{b}^{\prime}=0.871 & F_{S}^{\prime}=0.750 \\
a=1.446 & a_{b}=1.657 & a_{S}=2.309 & a_{s}=1.860
\end{array}
$$

\begin{tabular}{rccccccccc}
\multicolumn{1}{c}{$T_{1}$} & $\underline{T}_{1}-T_{\Omega}$ & $z^{*}$ & $z_{B}$ & $z^{* *}$ & $\mathcal{F}_{S}$ & $U_{L}$ & $\mathcal{F}_{S} \eta_{0}$ & $\mathcal{F}_{S} U_{L}$ & $\eta$ \\
-120.0 & -.280 & 0.983 & 0.017 & 0.0 & 0.469 & 3.003 & 0.394 & 1.407 & 0.788 \\
-110.0 & -.260 & 0.958 & 0.042 & 0.0 & 0.468 & 3.009 & 0.393 & 1.409 & 0.760 \\
-100.0 & -.240 & 0.931 & 0.069 & 0.0 & 0.468 & 3.015 & 0.393 & 1.411 & 0.732 \\
-90.0 & -.220 & 0.904 & 0.096 & 0.0 & 0.468 & 3.022 & 0.393 & 1.415 & 0.705 \\
-80.0 & -.200 & 0.876 & 0.124 & 0.0 & 0.469 & 3.030 & 0.394 & 1.420 & 0.678 \\
-70.0 & -.180 & 0.847 & 0.153 & 0.0 & 0.470 & 3.039 & 0.394 & 1.427 & 0.651 \\
-60.0 & -.160 & 0.816 & 0.184 & 0.0 & 0.471 & 3.049 & 0.396 & 1.436 & 0.625 \\
-50.0 & -.140 & 0.784 & 0.216 & 0.0 & 0.473 & 3.060 & 0.397 & 1.448 & 0.600 \\
-40.0 & -.120 & 0.750 & 0.250 & 0.0 & 0.476 & 3.073 & 0.400 & 1.462 & 0.575 \\
-30.0 & -.100 & 0.715 & 0.285 & 0.0 & 0.480 & 3.088 & 0.403 & 1.481 & 0.551 \\
-20.0 & -.080 & 0.677 & 0.323 & 0.0 & 0.485 & 3.105 & 0.407 & 1.505 & 0.528 \\
-10.0 & -.060 & 0.638 & 0.362 & 0.0 & 0.491 & 3.124 & 0.413 & 1.535 & 0.505 \\
0.0 & -.040 & 0.596 & 0.404 & 0.0 & 0.500 & 3.146 & 0.420 & 1.573 & 0.483 \\
10.0 & -.020 & 0.551 & 0.449 & 0.0 & 0.511 & 3.170 & 0.429 & 1.621 & 0.462 \\
20.0 & 0.0 & 0.503 & 0.497 & 0.0 & 0.526 & 3.198 & 0.442 & 1.682 & 0.442 \\
30.0 & 0.020 & 0.452 & 0.548 & 0.0 & 0.545 & 3.230 & 0.458 & 1.760 & 0.423 \\
40.0 & 0.040 & 0.397 & 0.603 & 0.0 & 0.570 & 3.265 & 0.479 & 1.862 & 0.405 \\
$\mathbf{5 0 . 0}$ & 0.060 & 0.337 & 0.663 & 0.0 & 0.604 & 3.304 & 0.507 & 1.996 & 0.388 \\
60.0 & 0.080 & 0.271 & 0.729 & 0.0 & 0.649 & 3.347 & 0.546 & 2.174 & 0.372 \\
70.0 & 0.100 & 0.198 & 0.802 & 0.0 & 0.712 & 3.393 & 0.598 & 2.416 & 0.357 \\
80.0 & 0.120 & 0.116 & 0.884 & 0.0 & 0.800 & 3.441 & 0.672 & 2.753 & 0.342 \\
92.4 & 0.145 & 0.0 & 1.000 & 0.0 & 0.968 & 3.500 & 0.813 & 3.388 & 0.323 \\
92.4 & 0.145 & 0.0 & 0.0 & 1.000 & 0.293 & 4.000 & 0.246 & 1.171 & 0.076 \\
100.0 & 0.160 & 0.0 & 0.0 & 1.000 & 0.293 & 4.000 & 0.246 & 1.171 & 0.059 \\
110.0 & 0.180 & 0.0 & 0.0 & 1.000 & 0.293 & 4.000 & 0.246 & 1.171 & 0.035
\end{tabular}


Tabie 1. (Continued)

$$
I^{* *}=706.7 w / m^{2}
$$

\begin{tabular}{|c|c|c|c|c|c|c|c|c|c|}
\hline$F^{\prime}=$ & 387 & $F_{B}^{\prime}=0.9$ & & 0.871 & $F_{S}^{\prime}=$ & 39 & $F_{s}^{\prime}=0$ & & \\
\hline$a=$ & 46 & $a_{b}=1.65$ & & 2.416 & $a_{8}=$ & U & & & \\
\hline$T_{1}$ & $\frac{T_{1}-T_{a}}{I}$ & $z^{*}$ & $z_{B}$ & $z^{* *}$ & $\mathcal{F}_{S}$ & $U_{L}$ & $\bar{f}_{S} \eta_{0}$ & $\digamma_{S} U_{L}$ & $\eta$ \\
\hline 120.0 & -.198 & 0.686 & 0.314 & 0.0 & 0.483 & 3.101 & 0.406 & 1.499 & 0.703 \\
\hline 110.0 & -.184 & 0.665 & 0.335 & 0.0 & 0.487 & 3.111 & 0.409 & 1.514 & 0.688 \\
\hline 100.0 & -.170 & 0.643 & 0.357 & 0.0 & 0.490 & 3. 121 & 0.412 & 1.530 & 0.672 \\
\hline-90.0 & -.156 & 0.621 & 0.379 & 0.0 & 0.495 & 3. 132 & 0.115 & 1.549 & 0.657 \\
\hline-80.0 & -.142 & 0.598 & 0.402 & 0.0 & 0.499 & 3. 144 & 0.419 & 1.570 & 0.642 \\
\hline-70.0 & -.127 & 0.575 & 0.425 & 0.0 & 0.505 & 3.157 & 0.424 & 1.594 & 0.627 \\
\hline-60.0 & -.113 & 0.550 & 0.450 & 0.0 & 0.511 & 3.171 & 0 . & 1.622 & 0.613 \\
\hline-50.0 & -.099 & 0.525 & 0.475 & 0.0 & 0.519 & 3.186 & 0.436 & 1.653 & 0.600 \\
\hline-40.0 & -.085 & 0.499 & 0.501 & 0.0 & 0.528 & 3.201 & 0.443 & 1.689 & 0.587 \\
\hline-30.0 & -.071 & 0.471 & 0.529 & 0.0 & 0.537 & 3.218 & 0.451 & 1.730 & 0.574 \\
\hline-20.0 & -.057 & 0.443 & 0.557 & $0 . c$ & 0.549 & 3.236 & 0.461 & 1.776 & 0.562 \\
\hline-10.0 & -.042 & 0.413 & 0.587 & 0 & 0.56 & 3.2 & 0.472 & 1.830 & 0.550 \\
\hline 0.0 & -.028 & 0.382 & 0.618 & 0. & 0.578 & 3.2 & 0.485 & 1.893 & 0.539 \\
\hline 10.0 & -.014 & 0.350 & 0.650 & 0.0 & 0.596 & 3.296 & 0.501 & 1.965 & 0.529 \\
\hline 20.0 & 0.0 & 0 & 0.685 & 0.5 & 0.618 & 3.318 & 0.519 & 2.049 & 0.519 \\
\hline 30.0 & 0 . & 0.2 & 0.721 & 0 & 0.6 & 3.341 & 0 . & 2.148 & 0.510 \\
\hline 40.0 & 0.028 & 0.242 & 0.758 & 0.0 & 0.67 & 3.366 & 0.565 & 2.264 & 0.501 \\
\hline 50.0 & 0.042 & 0.202 & 0.798 & 0.0 & 0.70 & 3.391 & 0.595 & 2.402 & 0.493 \\
\hline 60.0 & 0.057 & 0.159 & 0.841 & 0.0 & 0.75 & 3.416 & 0.631 & 2.567 & 0.486 \\
\hline 70.0 & 0.071 & 0.114 & 0.886 & 0.0 & 0.804 & 3.442 & 0.675 & 2.766 & 0.479 \\
\hline 80.0 & 0.085 & 0.065 & 0.935 & 0.0 & 0.867 & 3.468 & 0.729 & 3.008 & 0.473 \\
\hline 92.4 & 03 & 0.0 & 1.000 & 0.0 & 0.9 & 3.500 & & 3.388 & 0.466 \\
\hline 92.4 & & 0. & 0.0 & 1.00 & 0.2 & 4.250 & 0.234 & 1.184 & 0.113 \\
\hline 100.0 & 0.113 & 0.0 & 0.0 & 1.00 & 0.279 & 4.250 & 0.234 & 1.184 & 0.100 \\
\hline 110.0 & 0.127 & 0.0 & 0.0 & 1.000 & 0.279 & 4.250 & 0.234 & 1. 184 & 0.083 \\
\hline
\end{tabular}

$I=800 w / m^{2}$

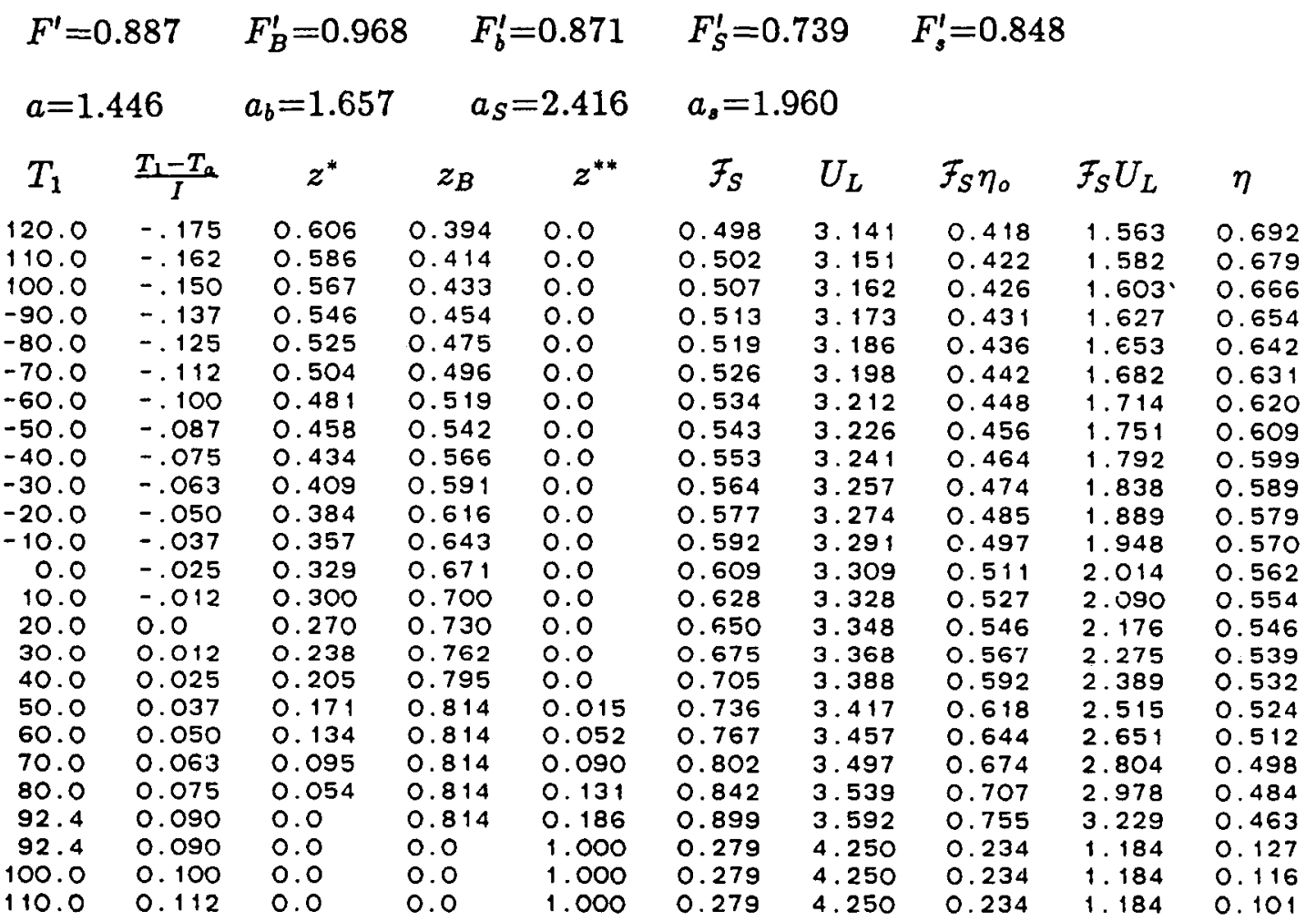


Table 1. (Continued)

\begin{tabular}{|c|c|c|c|c|c|c|c|c|c|}
\hline$F^{\prime}=$ & 887 & $F_{B}^{\prime}=0.96$ & & 0.871 & $F_{S}^{\prime}=$ & 728 & $F_{s}^{\prime}=0.84$ & & \\
\hline$a=1$ & 46 & $a_{b}=1.65$ & & 2.520 & $a_{s}=$ & 57 & & & \\
\hline$T_{1}$ & $\frac{T_{1}-T_{a}}{I}$ & $z^{*}$ & $z_{B}$ & $z^{* *}$ & $F_{S}$ & $U_{L}$ & $\mathcal{F}_{S} \eta_{0}$ & $\mathcal{F}_{S} U_{L}$ & $\eta$ \\
\hline-120.0 & -.156 & 0.540 & 0.460 & 0.0 & 0.514 & 3.177 & 0.432 & 1.635 & 0.686 \\
\hline-110.0 & -.144 & 0.522 & 0.478 & 0.0 & 0.520 & 3. 187 & 0.437 & 1.657 & 0.676 \\
\hline-100.0 & -.133 & 0.504 & 0.496 & 0.0 & 0.526 & 3. 198 & 0.442 & 1.682 & 0.666 \\
\hline-90.0 & -.122 & 0.485 & 0.515 & 0.0 & 0.532 & 3.210 & 0.447 & 1.709 & 0.656 \\
\hline-80.0 & -.111 & 0.465 & 0.535 & 0.0 & 0.540 & 3. 222 & 0.453 & 1.739 & 0.647 \\
\hline-70.0 & -.100 & 0.445 & 0.555 & 0.0 & 0.548 & 3.234 & 0.460 & 1.772 & 0.637 \\
\hline-60.0 & -.089 & 0.425 & 0.575 & 0.0 & 0.557 & 3.247 & 0.468 & 1.808 & 0.629 \\
\hline-50.0 & -.078 & 0.404 & 0.596 & 0.0 & 0.567 & 3.261 & 0.476 & 1.349 & 0.620 \\
\hline-40.0 & -.067 & 0.382 & 0.618 & 0.0 & 0.578 & 3.275 & 0.486 & 1.893 & 0.612 \\
\hline-30.0 & -.056 & 0.359 & 0.641 & 0.0 & 0.590 & 3.289 & 0.496 & 1.942 & 0.604 \\
\hline-20.0 & -.044 & 0.336 & 0.664 & 0.0 & 0.604 & 3. 305 & 0.508 & 1.997 & 0.596 \\
\hline-10.0 & -.033 & 0.312 & 0.678 & 0.010 & 0.618 & 3.326 & 0.519 & 2.055 & 0.588 \\
\hline 0.0 & -.022 & 0.287 & 0.678 & 0.035 & 0.630 & 3.356 & 0.529 & 2.114 & 0.576 \\
\hline 10.0 & -.011 & 0.261 & 0.678 & 0.061 & 0.643 & 3. 387 & 0.540 & 2.177 & 0.564 \\
\hline 20.0 & 0.0 & 0.234 & 0.678 & 0.087 & 0.657 & 3.420 & 0.552 & 2.246 & 0.552 \\
\hline 30.0 & 0.011 & 0.206 & 0.678 & 0.115 & 0.672 & 3.453 & 0.565 & 2.322 & 0.539 \\
\hline 40.0 & 0.022 & 0.177 & 0.678 & 0.145 & 0.690 & 3.488 & 0.579 & 2.405 & 0.526 \\
\hline 50.0 & 0.033 & 0.147 & 0.678 & 0.175 & 0.708 & 3.525 & 0.595 & 2.497 & 0.512 \\
\hline 60.0 & 0.044 & 0.115 & 0.678 & 0.207 & 0.729 & 3.563 & 0.613 & 2.599 & 0.497 \\
\hline 70.0 & 0.056 & 0.081 & 0.678 & 0.240 & 0.753 & 3.602 & 0.632 & 2.712 & 0.482 \\
\hline 80.0 & 0.067 & 0.046 & 0.678 & 0.276 & 0.779 & 3.643 & 0.655 & 2.839 & 0.465 \\
\hline 92.4 & 0.080 & 0.0 & 0.678 & 0.322 & 0.817 & 3.696 & 0.686 & 3.020 & 0.443 \\
\hline 92.4 & 0.080 & 0.0 & 0.0 & 1.000 & 0.266 & 4.500 & 0.223 & 1. 195 & 0.127 \\
\hline 100.0 & 0.089 & 0.0 & 0.0 & 1.000 & 0.266 & 4.500 & 0.223 & 1.195 & 0.117 \\
\hline 1100 & 0.100 & 0.0 & 0.0 & 1.000 & 0.266 & 4.500 & 0.223 & 1. 195 & 0.104 \\
\hline
\end{tabular}

$$
I=1000 w / m^{2}
$$

$$
\begin{array}{lllll}
F^{\prime}=0.887 & F_{B}^{\prime}=0.968 & F_{b}^{\prime}=0.871 & F_{S}^{\prime}=0.707 & F_{s}^{\prime}=0.827 \\
a=1.446 & a_{b}=1.657 & a_{S}=2.719 & a_{s}=2.247
\end{array}
$$

\begin{tabular}{rlllllllll}
\multicolumn{1}{c}{$T_{1}$} & $T_{1}-T_{a}$ & $z^{*}$ & $z_{B}$ & $z^{* *}$ & $\mathcal{F}_{S}$ & $U_{L}$ & $\mathcal{F}_{S} \eta_{0}$ & $\mathcal{F}_{S} U_{L}$ & $\eta$ \\
-120.0 & -.140 & 0.487 & 0.513 & 0.0 & 0.532 & 3.208 & 0.416 & 1.705 & 0.685 \\
-110.0 & -.130 & 0.471 & 0.529 & 0.0 & 0.538 & 3.218 & 0.452 & 1.731 & 0.677 \\
-100.0 & -.120 & 0.454 & 0.546 & 0.0 & 0.545 & 3.229 & 0.457 & 1.758 & 0.668 \\
-90.0 & -.110 & 0.436 & 0.564 & 0.0 & 0.552 & 3.240 & 0.464 & 1.788 & 0.660 \\
-80.0 & -.100 & 0.418 & 0.581 & 0.001 & 0.560 & 3.252 & 0.470 & 1.821 & 0.652 \\
-70.0 & -.090 & 0.400 & 0.581 & 0.019 & 0.565 & 3.276 & 0.474 & 1.850 & 0.641 \\
-60.0 & -.080 & 0.381 & 0.581 & 0.038 & 0.570 & 3.301 & 0.479 & 1.881 & 0.629 \\
-50.0 & -.070 & 0.361 & 0.581 & 0.058 & 0.575 & 3.327 & 0.483 & 1.915 & 0.617 \\
-40.0 & -.060 & 0.341 & 0.581 & 0.078 & 0.581 & 3.354 & 0.488 & 1.950 & 0.605 \\
-30.0 & -.050 & 0.320 & 0.581 & 0.098 & 0.588 & 3.382 & 0.494 & 1.989 & 0.593 \\
-20.0 & -.040 & 0.299 & 0.581 & 0.120 & 0.595 & 3.412 & 0.500 & 2.030 & 0.581 \\
-10.0 & -.030 & 0.277 & 0.581 & 0.142 & 0.602 & 3.443 & 0.506 & 2.074 & 0.568 \\
0.0 & -.020 & 0.255 & 0.581 & 0.164 & 0.611 & 3.475 & 0.513 & 2.122 & 0.555 \\
10.0 & -.010 & 0.231 & 0.581 & 0.188 & 0.620 & 3.509 & 0.521 & 2.174 & 0.542 \\
20.0 & 0.0 & 0.207 & 0.581 & 0.212 & 0.629 & 3.545 & 0.529 & 2.231 & 0.529 \\
30.0 & 0.010 & 0.182 & 0.581 & 0.237 & 0.640 & 3.582 & 0.538 & 2.293 & 0.515 \\
40.0 & 0.020 & 0.156 & 0.581 & 0.263 & 0.652 & 3.621 & 0.548 & 2.361 & 0.500 \\
50.0 & 0.030 & 0.129 & 0.581 & 0.290 & 0.665 & 3.662 & 0.559 & 2.435 & 0.486 \\
60.0 & 0.040 & 0.100 & 0.581 & 0.319 & 0.679 & 3.705 & 0.571 & 2.517 & 0.470 \\
70.0 & 0.050 & 0.071 & 0.581 & 0.348 & 0.696 & 3.750 & 0.584 & 2.608 & 0.454 \\
80.0 & 0.060 & 0.040 & 0.581 & 0.379 & 0.714 & 3.797 & 0.650 & 2.710 & 0.437 \\
92.4 & 0.072 & 0.0 & 0.581 & 0.419 & 0.739 & 3.859 & 0.621 & 2.853 & 0.414 \\
92.4 & 0.072 & 0.0 & 0.0 & 1.000 & 0.243 & $\mathbf{5 . 0 0 0}$ & 0.264 & 1.214 & 0.116 \\
100.0 & 0.080 & 0.0 & 0.0 & 1.000 & 0.243 & 5.000 & 0.204 & 1.214 & 0.107 \\
110.0 & 0.090 & 0.0 & 0.0 & 1.000 & 0.243 & 5.000 & 0.204 & 1.214 & 0.095
\end{tabular}


Table 1. (Continued)

\begin{tabular}{|c|c|c|c|c|c|c|c|c|c|}
\hline \multicolumn{10}{|c|}{$I=1100 w / m^{2}$} \\
\hline \multirow{2}{*}{\multicolumn{2}{|c|}{$\begin{array}{l}F^{\prime}=0.887 \\
a=1.446\end{array}$}} & \multicolumn{2}{|c|}{$F_{B}^{\prime}=0.968$} & $F_{b}^{\prime}=0.871$ & \multicolumn{2}{|c|}{$F_{S}^{\prime}=0.687$} & \multicolumn{3}{|c|}{$F_{s}^{\prime}=0.813$} \\
\hline & & $a_{b}=1.65$ & \multicolumn{2}{|c|}{$a_{S}=2.907$} & \multicolumn{2}{|c|}{$a_{s}=2.430$} & & & \\
\hline$T_{1}$ & $\frac{T_{1}-T_{a}}{I}$ & $z^{*}$ & $z_{B}$ & $z^{* *}$ & $\mathcal{F}_{S}$ & $U_{L}$ & $\digamma_{S} \eta_{o}$ & $\xi_{S} U_{L}$ & $\eta$ \\
\hline .120 .0 & -.127 & 0.444 & 0.508 & 0.047 & 0.537 & 3.267 & 0.451 & 1.754 & 0.674 \\
\hline .110 .0 & -.118 & 0.429 & 0.508 & 0.063 & 0.539 & 3.289 & 0.4 & 1.773 & 0.662 \\
\hline .100 .0 & -.109 & 0.413 & 0.508 & 0.079 & 0.542 & 3.311 & 0.455 & 1.794 & 0.651 \\
\hline-90.0 & -.100 & 0.396 & 0.508 & 0.095 & 0.545 & 3.334 & 0.457 & 1.816 & 0.639 \\
\hline-80.0 & -.091 & 0.380 & 0.508 & 0.112 & 0.548 & 3.359 & 0.460 & 1.839 & 0.627 \\
\hline-70.0 & -.082 & 0.363 & 0.508 & 0.129 & 0.551 & 3.384 & 0.4 & 1.864 & 0.615 \\
\hline-60.0 & -.073 & 0.345 & 0.508 & 0.147 & 0.554 & 3.411 & 0.4 & 1.890 & 0.603 \\
\hline-50.0 & -.064 & 0.327 & 0.508 & 0.165 & 0.558 & 3.439 & 0.469 & 1.919 & 0.591 \\
\hline-40.0 & -.055 & 0.308 & 0.508 & 0.183 & 0.562 & 3.468 & 0.472 & 1.949 & 0.578 \\
\hline-30.0 & -.045 & 0.289 & 0.508 & 0.202 & 0.566 & 3.499 & 0.476 & 1.982 & 0.566 \\
\hline-20.0 & -.036 & 0.270 & 0.508 & 0.222 & 0.571 & 3.531 & 0.4 & 2.017 & 0.553 \\
\hline-10.0 & -.027 & 0.250 & 0.508 & 0.242 & 0.576 & 3.565 & 0.4 & 2.055 & 0.540 \\
\hline 0.0 & -.018 & 0.229 & 0.508 & 0.263 & 0.582 & 3.600 & 0.489 & 2.095 & 0.527 \\
\hline 10.0 & -.009 & 0.207 & 0.508 & 0.284 & 0.588 & 3.638 & 0.494 & 2.140 & 0.514 \\
\hline 20.0 & 0.0 & 0.185 & 0.508 & 0.306 & 0.595 & 3.677 & 0.500 & 2.188 & 0.500 \\
\hline 30.0 & 0.009 & 0.162 & 0.508 & 0.329 & 0.602 & 3.719 & 0.50 & 2.241 & 0.486 \\
\hline 40.0 & 0.018 & 0.139 & 0.508 & 0.353 & 0.611 & 3.763 & 0.513 & 2.298 & 0.471 \\
\hline 50.0 & 0.027 & 0.114 & 0.508 & 0.377 & 0.620 & 3.809 & 0.521 & 2.361 & 0.456 \\
\hline 60.0 & 0.036 & 0.089 & 0.508 & 0.403 & 0.630 & 3.858 & 0.529 & 2.430 & 0.441 \\
\hline 70.0 & 0.045 & 0.063 & 0.508 & 0.429 & 0.641 & 3.909 & 0.539 & 2.507 & 0.425 \\
\hline 80.0 & 0.055 & 0.035 & 0.508 & 0.456 & 0.654 & 3.964 & O 549 & 2.592 & 0.408 \\
\hline 92.4 & 0.066 & 0.0 & 0.508 & 0.492 & 0.672 & 4.035 & 0.564 & 2.711 & 0.386 \\
\hline 92.4 & 0.066 & 0.0 & 0.0 & 1.000 & 0.223 & 5.500 & 0.188 & 1.229 & 0.107 \\
\hline 100.0 & 0.073 & 0.0 & 0.0 & 1.000 & 0.223 & 5.500 & 0.188 & 1.229 & 0.098 \\
\hline 110.0 & 0.082 & 0.0 & 0.0 & 1.000 & 0.223 & 5.500 & 0.188 & 1.229 & 0.087 \\
\hline
\end{tabular}

$$
I=1200 w / m^{2}
$$

$\begin{array}{lllll}F^{\prime}=0.887 & F_{B}^{\prime}=0.968 & F_{b}^{\prime}=0.871 & F_{S}^{\prime}=0.668 & F_{s}^{\prime}=0.800 \\ a=1.446 & a_{b}=1.657 & a_{S}=3.084 & a_{s}=2.608\end{array}$

\begin{tabular}{rccccccccc}
\multicolumn{1}{c}{$T_{1}$} & $\frac{T_{1}-T_{a}}{I}$ & $z^{*}$ & $z_{B}$ & $z^{* *}$ & $\mathcal{F}_{S}$ & $U_{L}$ & $\mathcal{I}_{S} \eta_{0}$ & $\mathcal{F}_{S} U_{L}$ & $\eta$ \\
120.0 & -.117 & 0.409 & 0.452 & 0.140 & 0.522 & 3.363 & 0.438 & 1.755 & 0.643 \\
110.0 & -.108 & 0.394 & 0.452 & 0.154 & 0.523 & 3.386 & 0.440 & 1.772 & 0.632 \\
100.0 & -.100 & 0.379 & 0.452 & 0.169 & 0.525 & 3.410 & 0.441 & 1.790 & 0.620 \\
-90.0 & -.092 & 0.364 & 0.452 & 0.185 & 0.527 & 3.435 & 0.442 & 1.809 & 0.608 \\
-80.0 & -.083 & 0.348 & 0.452 & 0.200 & 0.528 & 3.461 & 0.444 & 1.829 & 0.596 \\
-70.0 & -.075 & 0.332 & 0.452 & 0.216 & 0.531 & 3.489 & 0.446 & 1.851 & 0.584 \\
-60.0 & -.067 & 0.315 & 0.452 & 0.233 & 0.533 & 3.518 & 0.447 & 1.874 & 0.572 \\
-50.0 & -.058 & 0.299 & 0.452 & 0.250 & 0.535 & 3.548 & 0.449 & 1.899 & 0.560 \\
-40.0 & -.050 & 0.281 & 0.452 & 0.267 & 0.538 & 3.580 & 0.452 & 1.925 & 0.548 \\
-30.0 & -.042 & 0.264 & 0.452 & 0.284 & 0.541 & 3.614 & 0.454 & 1.954 & 0.536 \\
-20.0 & -.033 & 0.246 & 0.452 & 0.303 & 0.544 & 3.650 & 0.457 & 1.985 & 0.523 \\
-10.0 & -.025 & 0.227 & 0.452 & 0.321 & 0.547 & 3.688 & 0.460 & 2.018 & 0.510 \\
0.0 & -.017 & 0.208 & 0.452 & 0.340 & 0.551 & 3.727 & 0.463 & 2.054 & 0.497 \\
10.0 & -.008 & 0.188 & 0.452 & 0.360 & 0.555 & 3.769 & 0.466 & 2.093 & 0.484 \\
20.0 & 0.0 & 0.168 & 0.452 & 0.380 & 0.560 & 3.813 & 0.470 & 2.135 & 0.470 \\
30.0 & 0.008 & 0.147 & 0.452 & 0.401 & 0.565 & 3.860 & 0.475 & 2.181 & 0.456 \\
40.0 & 0.017 & 0.125 & 0.452 & 0.423 & 0.571 & 3.909 & 0.479 & 2.232 & 0.442 \\
50.0 & 0.025 & 0.103 & 0.452 & 0.445 & 0.577 & 3.962 & 0.485 & 2.287 & 0.428 \\
60.0 & 0.033 & 0.080 & 0.452 & 0.468 & 0.584 & 4.017 & 0.491 & 2.347 & 0.413 \\
70.0 & 0.042 & 0.056 & 0.452 & 0.492 & 0.592 & 4.076 & 0.498 & 2.414 & 0.397 \\
80.0 & 0.050 & 0.032 & 0.452 & 0.516 & 0.601 & 4.138 & 0.505 & 2.488 & 0.381 \\
92.4 & 0.060 & 0.0 & 0.452 & 0.548 & 0.614 & 4.219 & 0.516 & 2.591 & 0.359 \\
92.4 & 0.060 & 0.0 & 0.0 & 1.000 & 0.207 & 6.000 & 0.174 & 1.240 & 0.099 \\
100.0 & 0.067 & 0.0 & 0.0 & 1.000 & 0.207 & 6.000 & 0.174 & 1.240 & 0.091 \\
110.0 & 0.075 & 0.0 & 0.0 & 1.000 & 0.207 & 6.000 & 0.174 & 1.240 & 0.081
\end{tabular}


including the effects of exit superheat, are described as those states falling between the limits of $z^{* *}=$ $0.0, z^{*}=0.0$, and $z_{B}=0.0$, the region bounded by the curved triangle in Fig. 3 .

Another limiting situation corresponds to an inlet condition of single-phase vapor flow represented in Fig. 3 as point $D$, the state corresponding to $z^{*}=$ $0.0, z^{* *}=1.0$, and $z_{B}=0.0$. For this condition, $\mathscr{F}_{S}$ is equal to $F_{R S}$, eqn (35), the description of a singlephase vapor flow. For these specific operating conditions, this represents the minimum possible value of $F_{s}$. Another set of possible, though unusual, operating conditions are those having inlet states ranging from that of a saturated liquid $\left(C\right.$, inlet quality $x_{i}$ $=0.0$ ) to that of a saturated vapor (D, $x_{i}=1.0$ ). These are described by the path from $C$ to $D$, Figs. 3 and 4 , at $z^{*}=0.0$.

Accordingly, for any fixed set of operating conditions (i.e., $I, T_{1}, T_{a}, w / A_{c}$ ), type of fluid, etc, there will exist a general representation of all possible operating states, similar to Figs. 3 and 4 , describing the thermal performance of a flat-plate collector in nonboiling, boiling, and superheating flows.

The new Overall Thermal Loss Coefficient, $U_{L}$. defined by eqn (45), is a weighted average of the thermal loss coefficients $U_{N B}, U_{B}$, and $U_{S}$ in each of the different flow regions and is general in the sense that it is also used to describe the thermal losses of the flat-plate collector under any operating mode. For nonboiling conditions, that is $z^{*}=1.0$ and $z^{* *}=$ 0.0 , eqn (45) is reduced to $U_{L}=U_{N B}$. Also, for fully superheated conditions, $z^{* *}=1.0$, eqn (45) is reduced to $U_{L}=U_{S}$. Figure 4 shows values of $U_{L}$ as a function of $z^{*}$ and $z^{* *}$ for the same fixed operating conditions used in the simulation for Fig. 3 and for values of $U_{N B}, U_{B}$, and $U_{S}$ equal to $3.0,3.5$, and 5.0 $\mathrm{W} / \mathrm{m}^{2} \mathrm{~K}$, respectively, as determined for the conditions of this simulation by the method of Klein[2]. These results also point to an important fact concerning the representation of the thermal performance of flat-plate collectors in general. That is, although eqn (1) is a proper representation of the thermal efficiency, it is also a highly nonlinear representation, since over a range of operating conditions $U_{L}$ will change significantly, especially when a portion of the coolant channel is cooled by a superheated vapor. The points A, B, C, D, and E of Fig. 3 are also shown on Fig. 4.

For the case of flat-plate collector having a subcooled inlet condition and two-phase, saturated exit states, which has been studied by Al-Tamimi and Clark[11] and Clark[12] and reevaluated by El-Assy and Clark[18], the Overall Thermal Loss Coefficient, $U_{L}$, is a function only of $z^{*}$ and its variation is described by the curve for $z^{* *}=0.0$ (A-B-D) in Fig. 4. As may be noted the assumption of a constant $U_{L}$, as made in references [11] and [12] for this case, is a reasonable one, especially for the common situation for which $z^{*}$ varies between 0.0 and 0.2 . However, recent studies by the authors[18] provide a more complete evaluation of this situation. Where signif- icant portions of the coolant channels contain superheated vapor (large $z^{* *}$ ), the assumption of constant $U_{L}$ is no longer a valid approximation and provision must be made for consideration of its variation along the collector surtace.

To demonstrate the effects of inlet subcooling ( $T_{\text {sat }}$ $-T_{1}$ ) on the efficiency of a collector having superheated exit states, the thermal efficiency. eqn (48), with $U_{L}$ from eqn (45). is given in Fig. 5 for $I=$ $1000 \mathrm{~W} / \mathrm{m}^{2}$ for the same operating parameters of Figs. 3 and 4 , except that the inlet temperature. $T_{1}$. is increased from $20^{\circ} \mathrm{C}$ to $110^{\circ} \mathrm{C}\left(T_{\text {sat }}=92.4^{\circ} \mathrm{C}\right)$. The thermal efficiencies that correspond to all liquid (point A) and all vapor (point D) flows for these same parameters are included for comparison. The optical efficiency $\eta_{0}$ is taken as 0.841 . For $\left(T_{1}-T_{a}\right) / I$ equal to $0.072 \mathrm{~K} \mathrm{~m}^{2} / \mathrm{W}$, the inlet liquid flow is saturated. This represents one limit of operation for the boiling collector in two-phase states. Should a saturated liquid-vapor mixture $\left(0.0 \leq x_{i} \leq 1.0\right)$ enter the collector, its thermal efficiency would be reduced as indicated by path C-D, Fig. 5. Path C-D represents all saturated inlet states from saturated liquid, point $C$. $\left(x_{i}=0.0\right)$ to saturated vapor, point D. $\left(x_{i}=1.0\right)$ with the limit being point $D$, corresponding to a saturated vapor inlet state.

For this simulation, the values of $z^{*},=* *, \bar{F}_{s}$, and $U_{L}$ producing the collector thermal efficiency in Fig. 5 are summarized in Table 1 for $I=1000 \mathrm{~W} / \mathrm{m}^{2}$. As will be noted for $\left(T_{1}-T_{a}\right) / I=0.0$, the collector coolant channel is in nonboiling, boiling. and superheated operating states (point $\mathrm{E}, z^{*}=0.207$ and $z^{* *}$ $=0.212)$. With an increase in the inlet temperature $T_{1}$ (or decrease in inlet subcooling) from $20^{\circ} \mathrm{C}$ to its saturation value, $92.4^{\circ} \mathrm{C}$, the thermal efficiency is reduced significantly while the nonboiling region is reduced to zero $\left(z^{*}=0.0\right)$ and the superheated region is increased $\left(z^{* *}=0.419\right)$. Since the simulation is for constant $I\left(1000 \mathrm{~W} / \mathrm{m}^{2}\right)$ the boiling length $z_{B}$ will be unchanged, as shown by eqn (23), by decreases in inlet subcooling. The slope of the efficiency curve increases with $\left(T_{1}-T_{a}\right) / I$ as $T_{1}$ is increased due to increased thermal losses resulting from the higher plate temperatures associated with the superheated region. Points $\mathrm{C}$ and E, Fig. 5, are also shown in Figs. 3 and 4 to illustrate the changing conditions along the coolant channel, including the increase in the overall thermal loss coefficient, $U_{L}$, with increases in the fractional superheated channel length, $z^{* *}$.

A more general simulation, which describes the simultaneous influence of both inlet subcooling and incident solar radiation on the conversion efficiency, is shown in Fig. 6 with the detailed results summarized in Table 1 . To provide a basis for comparison of the thermal performance of the various operating modes, the conversion efficiency, $\eta$, is also shown for certain limiting conditions. These are (1) all subcooled liquid flow (A-A, $z^{*}=1.0$ ), (2) all vapor flow (D-D, $z^{* *}=1.0$ ), and (3) a fully boiling flow with a saturated liquid inlet condition and saturated liquid-vapor exit conditions $\left(\mathrm{F}-\mathrm{F}, z^{*}=0.0, z^{* *}=\right.$ 
$0.0, z_{B}=1.0$ ). Points A, B, C, D, and E shown in Figs. 3, 4, and 5 are included to assist in the interpretation of these results. Point B, which corresponds to a subcooled liquid inlet state and a saturated vapor exit state $\left(z^{*}=0.2, z_{B}=0.8, z^{* *}=0.0, x_{B}=1.0\right)$, represents a circumstance in which the condition of the coolant at the exit is in an incipient superheated state, that is, it becomes superheated with further increase in $l$ or decrease in inlet subcooling. This state is shown in Fig. 6 for $l=800 \mathrm{~W} / \mathrm{m}^{2}$ as determined by the simulation. As may be seen, point $B$ represents those circumstances that provide the maximum conversion efficiency that can be obtained for a collector having a saturated vapor exit state for fixed conditions of $I$ and inlet subcooling. Accordingly, point $B$ describes an important class of limiting states that will exist under all operating conditions that correspond to $z^{*} \geq 0.0$ and $z^{* *}=0.0$. The locus of points $\mathrm{B}$ for various values of $I$ is also shown in Fig. 6 .

For collectors having a fully boiling operating mode $\left(z^{* *}=0.0\right)$ and with saturated liquid-vapor exit states
$\left(z_{B}=1.0\right.$ and $\left.z^{* *}=0.0\right)$, there is a limiting value of $l$, defined as $l^{* *}$. at which the exit state is that of a saturated vapor. For $I$ greater than $I^{* *}$, superheated vapor states will be produced at the exit. $I^{* *}$ may be determined[18] using eqn (22) for $x_{B}=1.0$ as

$I^{* *}=\frac{U_{B}\left(T_{\mathrm{sat}}-T_{a}\right)}{\eta_{0}}\left[1+\frac{h_{f g} / c_{p l}\left(T_{\mathrm{sat}}-T_{a}\right)}{a\left(F_{B}^{\prime} / F^{\prime}\right)\left(U_{B} / U_{N B}\right)}\right]$

For the conditions of this simulation $I^{* *}=706.7 \mathrm{~W} /$ $\mathrm{m}^{2}$. It will be also recognized that $I^{* *}$ further defines the limits of the operating states of a boiling collector since for $I<I^{* *}$ no superheated exit states are possible.

The states describing a boiling flat-plate collector having subcooled liquid inlet states and exit states consisting of a saturated liquid-vapor mixture all fall within the limits shown in Fig. 6 as curves for points $A, F$, and $B$ with transition to superheated exit states

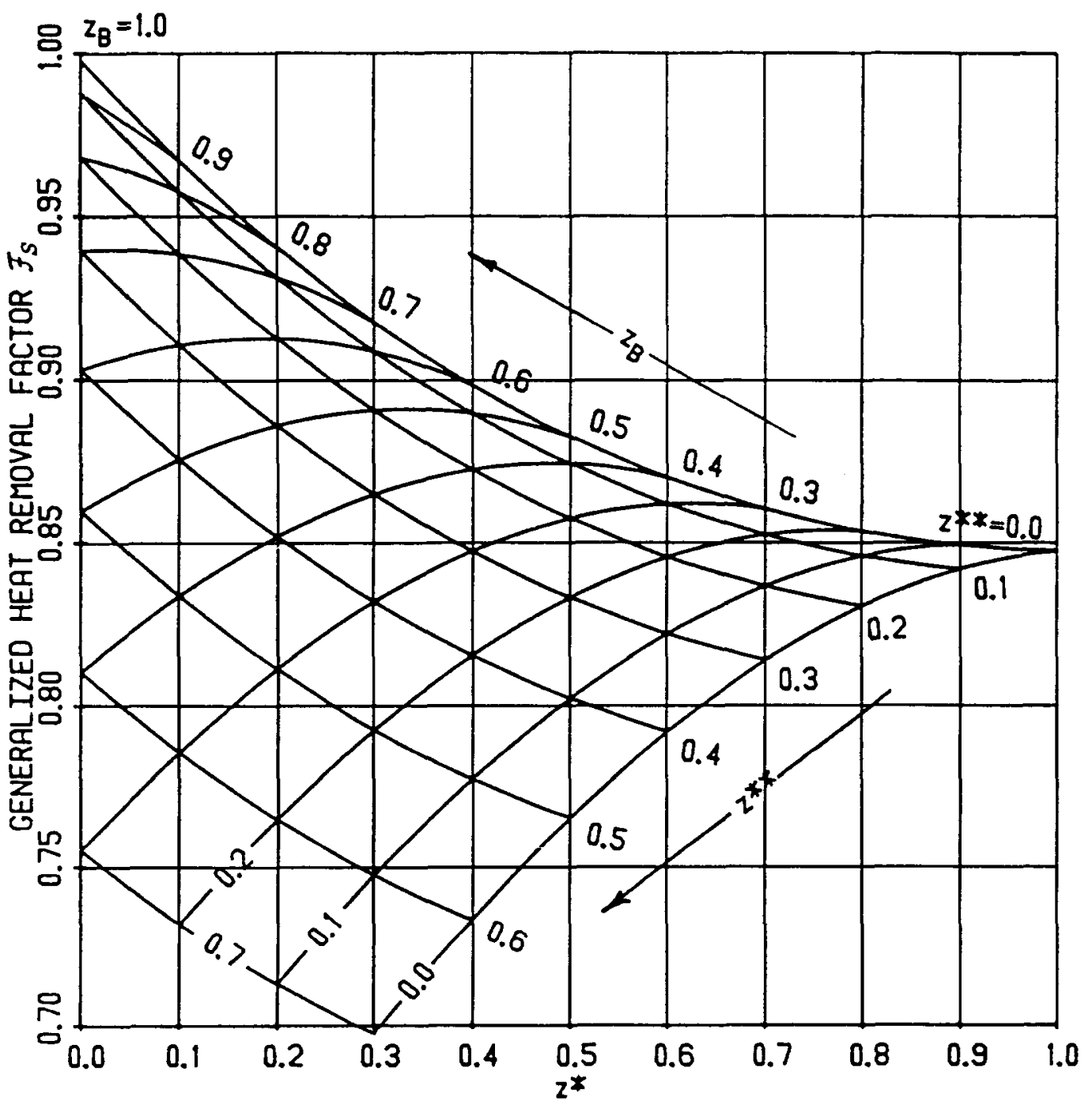

Fig. 7. Generalized heat removal factor $F_{s}$ for $R=1$ for a compound parabolic concentrator from [13, 14]. 
defined by $I^{* *}$. eqn (54). These operating conditions are those studied by AI-Tamimi and Clark[11] and Clark[12]. This work has recently been reexamined by the authors[18] and some of the results are included in Fig. 6 (dashed lines) for completeness but without further discussion. Note, however, that the thermal performance of boiling collectors of this type are described by a family of curves of constant $I$ and represent a transition region between collectors operating in a fully nonboiling mode and those operating in a fully boiling mode.

The conversion efficiency for collectors having superheated exit states is shown in Fig. 6 (solid lines) for conditions corresponding to $I \geq I^{* *}$. For subcooled inlet liquid states, the efficiency is reduced for decreases in inlet subcooling for all values of $I$ in excess of $I^{* *}$. This demonstrates the significant effect of increased thermal losses associated with the higher absorber plate temperatures in the superheated regions of the collector. The data of these conditions are summarized in Table 1.

The nonlinear characteristics inherent in the thermal performance of boiling collectors makes it dif- ficult to simulate their performance using models such as $f$-chart, which postulates knowledge of mean monthly operating parameters. The one exception is the fully boiling collector having saturated inlet and exit conditions $[11,12,19]$. However, should simulation be done on a smaller time scale, say hourly, then the present formulation could be used although the model would be more complex, as should be expected. The authors have used this type of simulation in energy system models having time intervals as small as $6 \mathrm{~s}$. Actually, the results presented here are themselves the product of a "simulation" process in that the analytical model was programmed on a computer for a wide range of parameter variation. Accordingly, a complete "system simulation" would be an extension of this modeling over any time period, including time-dependent heat capacity effects as well.

\section{EFFECT OF CONCENTRATION}

In a companion study, [13] and [14], the authors have analyzed the thermal performance of a compound parabolic concentrator (CPC) operating in sin-

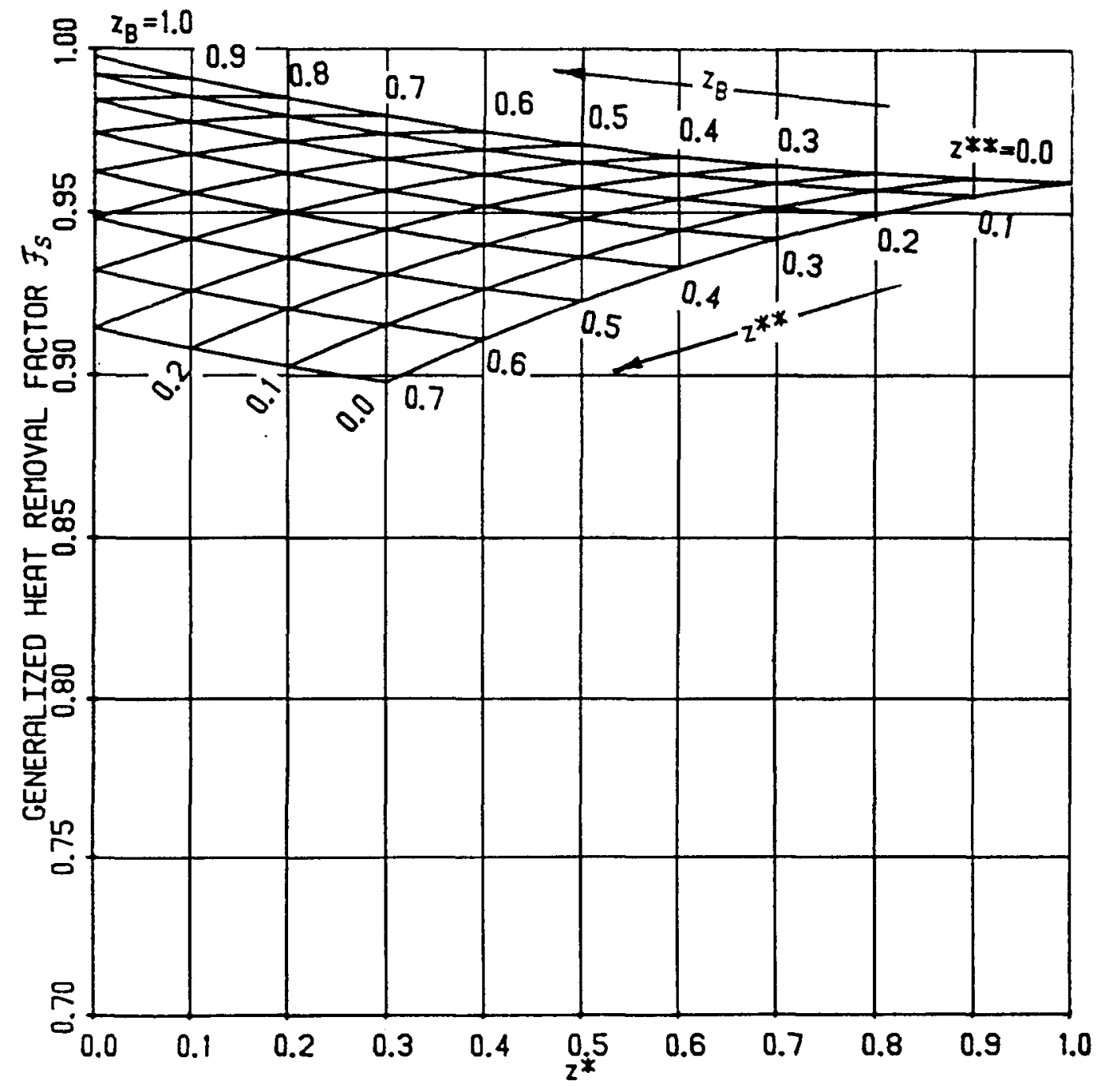

Fig. 8. Generalized heat removal factor $F_{S}$ for $R=5$ for a compound parabolic concentrator from [13, 14]. 
gle and multiphase flows, including exit superheat, for concentration ratios, $R$, from 1.0 to 5.0. Because that research bears significantly on the present study, some of the results are included here in Figs. 6, 7. and 8 , for $R=1.0$ and $R=5.0$. Due to geometric differences, the performance of a CPC at $R=1.0$ is not the same as that of a flat-plate collector, although there is a general similarity. This is evident from a comparison of Figs. 3 and 6 . The influence of concentration is significant on the enhancement of CPC performance as may be seen from Figs. 6 and 7. Furthermore, the improvement in thermal performance of a CPC at $R=5.0$ over that of a flat-plate collector is evident from a comparison of the results in Figs. 3 and 7.

Acknowledgments-The authors wish to acknowledge the interest and helpful support of this research by Mr. Edward W. Bottum. President. Refrigeration Research Inc., Solar Research Division, Brighton, Michigan, USA. Mr. Mahmoud Wali contributed to the analysis as a part of a graduate research project.

\section{REFERENCES}

1. H. C. Hottel and B. B. Woertz, Performance of flat plate solar-heat collectors. Trans. ASME, 64, 91 (1942).

2. S. A. Klein, Calculation of flat plate loss coefficients. Solar Energy, 17, 79 (1975).

3. V. K. Agarwal and D. C. Larsen, Calculation of the top loss coefficient of a flat plate collector. Solar Energy, 27, 69-71 (1981).

4. A. Malhotra, H. P. Garg and A. Palit, Heat loss calculation of flat plate solar collectors. J. Thermal Eng., 2, 2, (1981).

5. H. P. Garg and G. Datta, 'The Top Loss Calculation for Flat Plate Solar Collector,' Technical Note, Solar Energy, 32, 141-143 (1984).

6. H. C. Hottel and A. Whillier, Evaluation of flat plate collector performance. Trans Conference on the Use of Solar Energy, 2, 74 (1958).

7. R. W. Bliss, The derivation of several plate efficiency factors useful in the design of flat plate solar-heat collectors. Solar Energy, 3, 55 (1959).

8. J. E. Hill and T. Kusuda, Proposed standard method of testing for rating solar collectors based on thermal performance. National Bureau of Standards. Interim Report NBSIR 74-635 to NSF/ERDA (1974).

9. J. E. Hill and E. R. Streed, Testing and rating of solar collectors. Paper in Applications of Solar Energy for Heating and Cooling of Buildings, ASHRAE GRP 170 (1977).

10. J. E. Hill, J. P. Jenkins and D. E. Jones, Testing of solar collectors according to ASHRAE Standard 9377. ASHRAE Trans., 84, Part 2 (1978).

11. A. I. Al-Tamimi and J. A. Clark, Thermal analysis of a solar collector containing a boiling fluid. Proceedings, American Solar Energy Society Annual Meeting. Minneapolis. MN, June 1-3 (1983).

12. J. A. Clark. Analysis of the thermal performance of boiling collectors. Current Research in Heat and Mass Transfer. Proceedings of the Eighth National Heat and Mass Transfer Conference, India, 1985: Hemisphere Publishing Co. (1986).

13. A. Y. El-Assy. Technical and economic analysis of the thermal performance of a solar boiling concentrator for power generation. Ph.D. Thesis, The University of Michigan. Ann Arbor (1986).

14. A. Y. El-Assy and J. A. Clark, A thermal-optical analysis of a compound parabolic concentrator for single and multi-phase flows, including superheat. Warme und Stoffubertragung, vol. 21, pp. 189-198. Springer-Verlag, Berlin (1987).

15. J. A. Duffie and W. A. Beckman, Solar Engineering of thermal processes. Wiley, New York (1980).

16. C. K. Brown and W. H. Ganvin, Combined free and forced convection I and II. Canadian J. Chem. Eng., 43 (6). 306-313 (1965).

17. M. J. McNelly. A correlation of the rates of heat transfer to nucleate boiling liquids. J. Imperial College Chemical Engineering Society, 7, 18-34 (1953).

18. A. Y. El-Assy and J. A. Clark. A thermal analysis of a flat-plate boiling collector having sub-cooled inlet and saturated exit states. Manuscript submitted to Solar Energy. July 1987.

19. H. W. Price. S. A. Klein and W. A. Beckman. Analysis of boiling flat-plate collectors. J. Solar Energy Engineering. 108 (2), 150-158 (May 1986). 